\title{
Ofrendas para una entrada: un depósito ritual en la Puerta Oeste de la Bastida de les Alcusses (Moixent, Valencia)
}

\author{
Offerings for the gate: a ritual deposit at the West Gate of la Bastida de les Alcusses \\ (Moixent, Valencia)
}

\author{
Jaime Vives-Ferrándiz Sánchez (*) \\ Helena Bonet Rosado (*) \\ Yolanda Carrión Marco (**) \\ Carlos Ferrer García (*)
}

\author{
Pilar Iborra Eres $(* * *)$ \\ Guillem Pérez Jordà $(* * * *)$ \\ Fernando Quesada Sanz (*****) \\ Guillermo Tortajada Comeche (*)
}

\section{RESUMEN}

En este trabajo se dan a conocer los resultados de las excavaciones llevadas a cabo en la Puerta Oeste de la Bastida de les Alcusses entre los años 2010 y 2011. Asociado a una renovación de las estructuras de la entrada y la muralla, se documentó un depósito de varios centenares de objetos incluyendo herrajes, maderas, armas, cerámica, semillas, frutos, fauna y restos constructivos. Presentamos el estudio multidisciplinar de todos los materiales y las varias líneas de interpretación que nos sugiere este extraordinario contexto.

\section{ABSTRACT}

In this paper we present the results of the excavations carried out during 2010 and 2011 in the West Gate of

(*) Servicio de Investigación Prehistórica. Museo de Prehistoria de Valencia. C/ Corona 36. 46003 Valencia. Correos e.: jaime.vivesferrandiz@dival.es; helena.bonet@dival.es;

carlos.ferrer@dival.es; g.tortajada@gmail.com

(**) Dpto. de Geografía, Prehistoria y Arqueología, Universidad del País Vasco (UPV/EHU). C/ Tomás y Valiente s/n. 01006 Vitoria-Gasteiz. Correo e.: yolanda.carrion@uv.es

(***) Área Arqueología y Paleontología, CulturArts, Generalitat Valenciana. C/ Genaro Lahuerta 25, planta 3. 46010 Valencia. Correo e.: mpiborraeres@gmail.com

$(* * * *)$ Instituto de Historia, CCHS, CSIC. C/ Albasanz 2628. 28037 Madrid. Correo e.: guillem.perez@csic.es

(*****) Dpto. de Prehistoria y Arqueología. Universidad Autónoma de Madrid. Campus de Cantoblanco. 28049 Madrid. Correo e.: fernando.quesada@uam.es

Recibido 3-II-2015; aceptado 13-III-2015. the Iberian oppidum of la Bastida de les Alcusses. A ritual deposit of hundreds of items, including iron objects, charcoal, weapons, pottery, seeds, faunal remains and mud bricks, was recovered. After undertaking the study of all the materials, we offer several avenues of research that this extraordinary context suggests.

Palabras clave: Cultura ibérica; Edad del Hierro; Península Ibérica; País Valenciano; Ritualización; Cremación; Puerta; Oppidum; Armas de hierro; Carpintería; Arqueobiología.

Key words: Iberians; Iron Age; Iberian Peninsula; Valencia; Ritualization; Cremation; Gate; Oppidum; Iron weapons; Carpentry; Bioarchaeology.

\section{INTRODUCCIÓN}

La Bastida de les Alcusses (Moixent, Valencia) es un oppidum ibérico ocupado entre finales del siglo $\mathrm{V}$ a.C. y el tercer cuarto del siglo IV a.C. La muralla, las entradas fortificadas, los viales preparados para la circulación de carros, las manzanas de viviendas y los edificios públicos, como un lugar para reuniones y un gran almacén colectivo, indican su carácter de espacio del poder y residencia de élites. La muralla es un perímetro de forma aproximadamente elíptica de tendencia sinuosa. Tres puertas (Oeste, Norte y Sur) se abren en la parte occidental y una en el Este (Bonet y Vives-Ferrándiz 2011) (Fig. 1). 


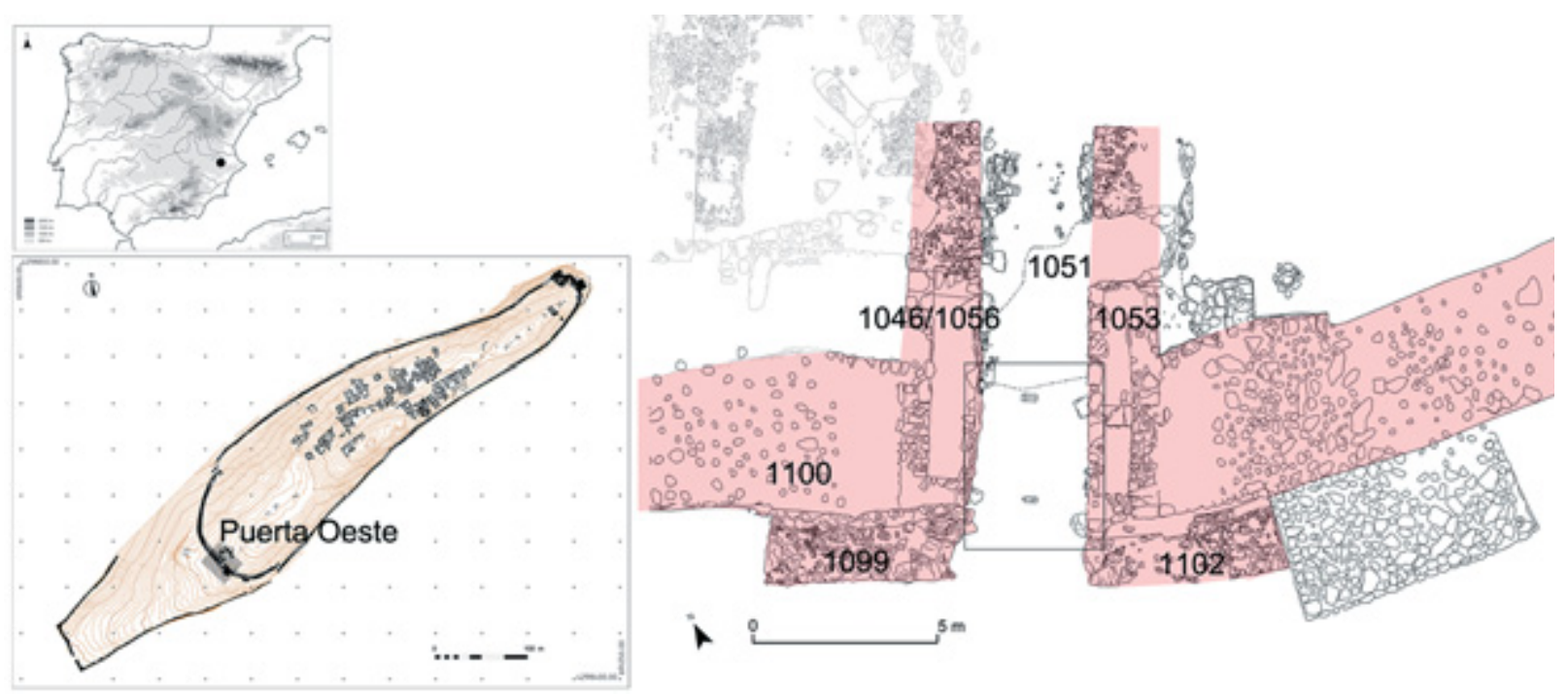

Fig. 1. Localización del yacimiento y detalle de las estructuras de la fase inicial de la Puerta Oeste. El recuadro en el centro del pasillo de la entrada indica la zona donde se halló el depósito ritual.

Como acceso principal en el frente de muralla la Puerta Oeste debió tener un carácter especial. De hecho, sobre el pavimento de su primera fase se documentó, en 2010 y 2011, un depósito de varios centenares de objetos incluyendo herrajes, maderas, armas, cerámica, semillas, frutos, restos de fauna y elementos constructivos. Este trabajo presenta, primero, los resultados de la excavación y del estudio de los materiales y, después, la reconstrucción de la secuencia ritual y varias líneas de interpretación de este contexto.

\section{LA EXCAVACIÓN}

Los primeros trabajos de excavación y consolidación de la Puerta Oeste y de la muralla se llevaron a cabo en 1998 (Díes 2005). En 2010 un sondeo practicado junto a su muro $\mathrm{N}$ (UE 1046/1056) reveló una fase anterior, desconocida, de la entrada (Bonet y Vives-Ferrándiz 2011: 239). Ante la importancia de este hecho, el sondeo se amplió a un área de 2,60 x 2,30 m delimitada por el umbral, los muros de la puerta y una gran fosa en la parte posterior de cronología más reciente (UE 1051). En 2011 la excavación prosiguió en la parte exterior del umbral (Fig. 1). Desde entonces, y hasta el momento de redac- tar estas líneas, estamos documentado una compleja historia constructiva en el sector oeste del asentamiento con, al menos, cuatro fases. Dos corresponden, respectivamente, a la construcción y renovación de las estructuras defensivas de la muralla, de las torres y de la propia Puerta Oeste. Se fechan entre finales del siglo $\mathrm{V}$ y mediados del siglo IV a.C. Una fase anterior y otra posterior a estas construcciones están actualmente en estudio.

La excavación de 2010 comenzó documentando la UE 1054, que es un paquete de tierra con abundante material arqueológico cuya potencia oscilaba entre 50 y $90 \mathrm{~cm}$. Amortizaba la primera fase de la puerta y, a su vez, servía de pavimento de la segunda fase. Destacaban los restos carbonizados de madera de diverso tamaño, incluyendo grandes piezas trabajadas y troncos de gran calibre. Además se evidenciaba la presencia de fragmentos de lanzas, cerámica y restos constructivos. Bajo la UE 1054 se identificó la UE 1066, formada por una capa de unos 10-15 cm con herrajes, carbones, armas, cerámica, semillas o elementos constructivos, todo in situ sobre el pavimento de la primera entrada (UE 1055/1060). El área se cuadriculó $(50 \times 50 \mathrm{~cm})$ y se recogió todo el sedimento. En 1054 y 1066 todos los objetos fueron numerados, diferenciando los carbones del resto (Fig. 2). Al excavar 1066 se identificaron, entre el material depositado sobre el pavimento, 


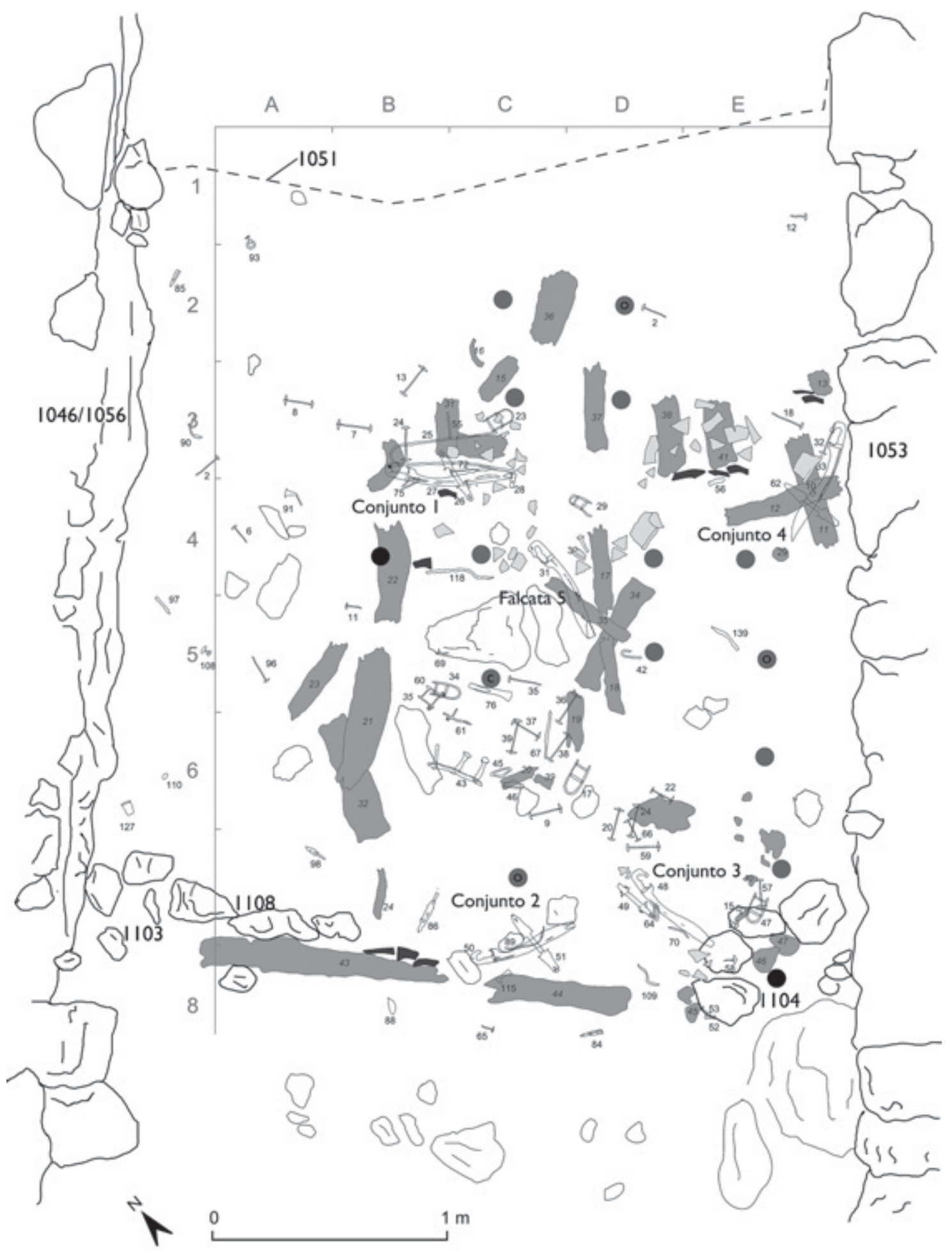

Fig. 2. Planta de los materiales hallados en las unidades 1054 y 1066. Todos los números hacen referencia al inventario (en cursiva los carbones, que mantienen una numeración separada del resto de objetos). Los círculos indican la presencia de fauna en ese cuadro (o: ovicaprino; c: ciervo; en negro si está quemada).

Trab. Prehist., 72, N. ${ }^{\circ}$ 2, julio-diciembre 2015, pp. 282-303, ISSN: 0082-5638

doi: $10.3989 /$ tp.2015.12155 
cinco lotes de objetos a partir de la presencia de una falcata en cada uno de ellos (conjuntos 1-5) aunque el quinto, ubicado en el centro geométrico del pasillo de la entrada, está formado sólo por una falcata. Las piezas de la UE 1054 están a pocos centímetros de distancia de los conjuntos, pero su asociación a alguno de ellos, aunque probable, no puede garantizarse.

La fase inicial de la Puerta Oeste está formada por dos grandes muros paralelos (UUEE 1046/1056 y 1053), dispuestos en sentido suroeste-noreste. Fueron construidos con bloques calizos locales escuadrados con cuidado sobre un relleno de margas (UE 1101) que regulariza los desniveles de la roca. Los muros tienen $2 \mathrm{~m}$ de ancho y $12,3 \mathrm{~m}$ de longitud y están rematados en dos contrafuertes (UE 1099 y UE 1102) que traban, a su vez, con la muralla (UE 1100). El pavimento está formado por tierra apisonada con grava (1-2 cm de tamaño) y piedras pequeñas (4-5 $\mathrm{cm}$ de tamaño). Buza algo hacia el exterior de la entrada. Está cortado por la fosa UE 1051 que también rompe, en parte, los muros de la puerta (UUEE 1053 y 1070). El suelo se numera como UUEE 1055/1060 al oeste de la fosa y como UE 1117 en la parte posterior de la entrada. En esta parte, el relleno que lo cubre es la UE 1050. Equivale a 1054 porque amortiza también los muros de la entrada, pero difiere de ella en que aquí no hay el mismo volumen de objetos.

En la parte anterior de la entrada se documentó un vano de 2,65 $\mathrm{m}$ y un umbral formado por una alineación de piedras medianas y pequeñas cubiertas en parte por el pavimento (UE 1108). Los mampuestos están quemados y protegen un tronco de sección cuadrangular $\left(\mathrm{n}^{\circ} 43\right.$ y 44) que se ha conservado parcialmente carbonizado in situ. En los extremos del umbral dos estructuras de planta pseudocircular (UUEE 1103 y 1104), formadas por mampuestos medianos sin trabajar y trabados con barro, se interpretaron como bases para alojar los montantes de las hojas de la puerta. La UE 1104 tenía abundantes restos de carbones asociados ( $\left.n^{\circ} 46\right)$ y los mampuestos mostraban evidentes señales de haber sufrido la acción del fuego in situ. En la parte exterior del umbral se constata un paquete poco potente de tierra (UE 1075) equivalente a la UE 1066, pero de la que difiere por su escaso contenido arqueológico. Es decir, el umbral delimita claramente el espacio reservado al depósito ritual en el interior de la entrada.

\section{LOS MATERIALES ARQUEOLÓGICOS}

\subsection{Herrajes de carpintería de hierro}

Son los objetos metálicos mayoritarios recuperados. De los 180 documentados en 1054 y 1066 hay 72 fragmentos de herrajes de carpintería. Corresponden a 58 objetos que pueden agruparse en tres tipos: remaches, pletinas remachadas y clavos.

Los remaches de cabeza hemisférica y placa romboidal son 35 (17 de ellos completos). La tija o vástago de sección cuadrada parte de la cabeza. En el otro extremo de la tija hay una chapita o plaquita de forma romboidal. Su centro está perforado y atravesado por el extremo final de la tija, que está remachado a golpes (Fig. 3: 1 y 2). Los 19 remaches medibles se agrupan en dos medidas de luz, equivalentes al espesor total de las piezas de madera a unir: seis remaches tienen una medida interior de $10 \mathrm{~cm}$ y 13 de unos 15 $\mathrm{cm}$. Su forma es inédita entre los 204 conocidos en el asentamiento hasta la fecha. La principal diferencia estriba en que el tipo hallado en la Puerta Oeste tiene la cabeza redonda solidaria a la tija mientras que los otros están formados por una varilla de sección cuadrada que se corta a la medida necesaria y se remacha a golpes. Mientras estos últimos son fácilmente adaptables a cualquier espesor de madera, el primero no, por lo que es un tipo de pieza fabricado ad hoc.

Las pletinas remachadas son de dos tipos: en forma de $U$ y rectas. Las primeras son 6 láminas curvas con un extremo abierto y el otro cerrado en $\mathrm{U}$, dispuestas en paralelo para unir tablas. $\mathrm{Su}$ morfología indica que siempre se coloca en el extremo de la puerta o tablero a unir. Miden unos 2,5 $\mathrm{cm}$ de anchura (salvo la $\mathrm{n}^{\mathrm{o}} 47 \mathrm{de} 4 \mathrm{~cm}$ ) y $35 \mathrm{~cm}$ de longitud, reducida a 13 y $14 \mathrm{~cm}$ al doblarla. La distancia interior de las pletinas varía entre 5,1 y $5,6 \mathrm{~cm}$ y equivale al grosor de la madera a unir. Dos o tres remaches se disponen longitudinalmente (Fig. 3: 4). Este tipo se ha documentado en otros contextos del asentamiento, sobre todo asociado a las puertas (Tortajada 2011: 81). Las medidas varían según se considere todo el contorno de la hoja (hasta $120 \mathrm{~cm}$ ) o las tablas del montante o larguero en el que está el pivote. Es tradicional el uso de herrajes similares para reparar puertas pivotantes en las zonas debilitadas 

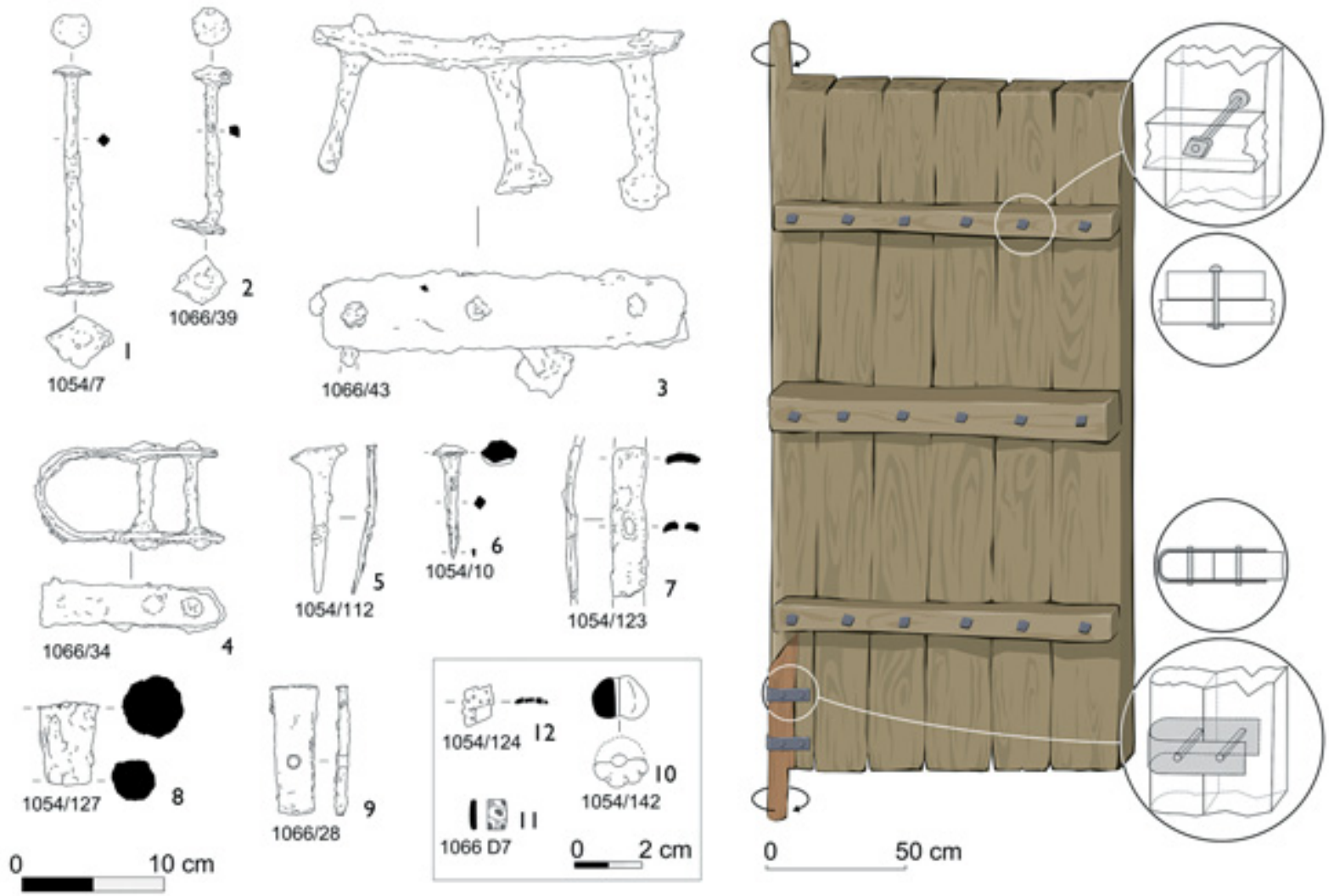

Fig. 3. Selección de materiales hallados en la Puerta Oeste. A la derecha propuesta de reconstrucción de una de las hojas de la puerta (dibujo A. Sánchez).

por la humedad, como la del pivote, que está en contacto directo con el suelo.

Contamos con un ejemplar completo de pletina recta plana y seis fragmentos de otras. El primero mide $26 \mathrm{~cm}$ de longitud y $5 \mathrm{~cm}$ de anchura. La atraviesan tres remaches de cabeza redonda en la parte de la pletina y un remache romboidal en la otra (Fig. 3: 3). Proponemos que es un elemento de reparación de los batientes de la puerta en algún punto débil, uniendo las tablas verticales y alguna de las traviesas.

Se han documentado 6 clavos triangulares planos (Fig. 3: 5), 5 de cabeza redonda (Fig. 3: 6) y 1 de dos puntas. El primer tipo es una lámina aguzada en su punta y ensanchada en su cabeza por los golpes para alojarlos. La forma laminar de este clavo, casi como una fina cuña, responde a un uso diferente al de los de tija de sección cuadrada: los clavos triangulares se clavan en el sentido de la veta de la madera sin apenas abrirla o deformarla. El tipo suele estar asociado a las llantas de rueda de carro por lo que es sugerente relacionar los ejemplares hallados con un posible fragmento de llanta de carro (véase más abajo), aunque no había ninguna conexión física directa entre ellos.

Otro herraje, hallado en la UE 1054 ( $\left.n^{\circ} 123\right)$, es un fragmento que identificamos como una llanta de hierro para rueda de carro (Fig. 3: 7). Hay ejemplares de llantas de este tipo en la propia Bastida de les Alcusses (departamentos 43, 53, 146, 181, 190 y 209).

\subsection{Madera}

En las unidades que nos ocupan abunda la madera carbonizada, entre la que se ha podido individualizar troncos y piezas labradas así como 
un sedimento muy rico en carbones de diverso tamaño, restos de la fragmentación de esas piezas, así como otros dispersos por el suelo. Se han distinguido y analizado 50 fragmentos, grandes piezas trabajadas y troncos de gran calibre. La identificación botánica de las maderas ha revelado la presencia casi exclusiva de pino (carrasco, excepto quizá un fragmento de pino piñonero) y unos pocos ejemplos de carrasca. Este panorama coincide con la madera de pino carrasco y de carrasca-coscoja predominante en la construcción en otros contextos del yacimiento, de modo que estas especies debieron de constituir la base del material de carpintería. El uso de los pinos y, concretamente, del pino carrasco, está ampliamente documentado en la construcción en yacimientos ibéricos (1) por sus propiedades físicas y mecánicas y por su disponibilidad y abundancia.

La morfología de la madera de origen ha sido casi imposible de determinar dado el alto índice de fragmentación por fuego. Hemos discernido si se trataba de troncos o ramas de menor calibre observando la curvatura de los anillos de crecimiento (menor cuanto más nos acercamos a la parte externa de un tronco de gran calibre), la presencia de corteza y/o médula y, en unos pocos casos, el reconocimiento de piezas con lados escuadrados, fruto del labrado humano de este material. Estas últimas son siempre de pino carrasco y algunas están asociadas además a clavos y pletinas. También había ramas de menor calibre, algunas de las cuales conservaban la corteza, lo que nos da su calibre real (en general menor de $5 \mathrm{~cm}$ de diámetro). Estas ramas con corteza nos informan, además, de la estación de tala de la planta. La madera varía su morfología a lo largo del año, ya que su crecimiento radial no es uniforme en las diferentes estaciones. La posición de la corteza en contacto con lo que se llama "madera final" nos dice que todas se cortaron durante la estación desfavorable para el crecimiento del árbol, esto es, entre el final de la primavera y el final del verano.

En general, las maderas tienden a una alta fragmentación. Sin embargo la acción heterogénea del fuego ha dejado sin carbonizar parte

(1) Grau, E. 1990: El uso de la madera en yacimientos valencianos de la Edad del Bronce a época visigoda. Datos etnobotánicos y reconstrucción ecológica según la antracología. Tesis Doctoral. Departament de Prehistòria i Arqueologia. Facultat de Geografia i Història, Universitat de València. de ellas por lo que ofrecen un amplio abanico de estados de conservación, además de las que probablemente han desaparecido por completo. De algunas piezas apenas se conservaba una impronta en el sedimento mientras de otras quedaba la parte externa afectada por el fuego pero no el interior degradado por completo. Hubo fragmentos de madera depositados en estado fresco que al pudrirse dejaron como único rastro una alineación de remaches (véanse los cuadros A-B/3-5, Fig. 2). Los insectos y microorganismos xilófagos, algunos de los principales agentes de la degradación de la madera, son frecuentes en las piezas del depósito. Una valoración conjunta de la presencia de estos agentes descomponedores y del calibre de las maderas ha revelado que la alteración es sensiblemente más frecuente en las de gran calibre, mientras las ramitas están más sanas (Fig. 4). Esto puede relacionarse con el uso de dos tipos de madera: unas pertenecientes a estructuras $\mathrm{y} / \mathrm{u}$ objetos muebles que pueden haber permanecido expuestas a la intemperie y atacadas durante el periodo de uso; otras maderas "frescas" (ramas principalmente) cortadas específicamente como combustible para la quema del conjunto.

Sin embargo, poco sabemos del combustible utilizado. Se recogieron de forma separada las piezas de madera y el sedimento directamente depositado sobre el suelo (UUEE 1066 y 1075), que contenía numerosos restos orgánicos, entre

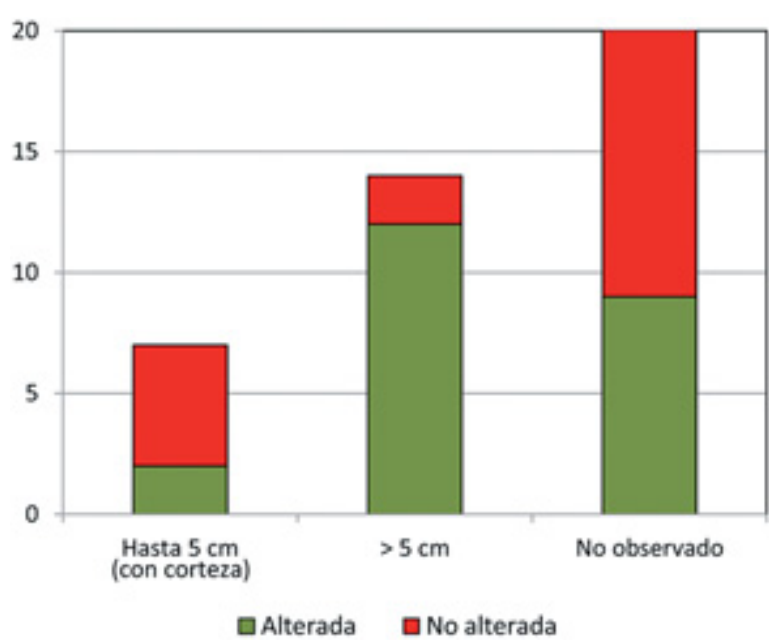

Fig. 4. Frecuencia de la alteración de la madera por agentes xilófagos según el calibre. 
ellos carbones, de tamaño y morfología variable (Tab. 1). De nuevo el predominio de pino, y carrasca-coscoja en segundo lugar, es absoluto quizá porque los carbones procedan de la fragmentación de las piezas anteriormente descritas, aunque aquí sí podemos observar la presencia de ramitas de pequeño calibre. Otras especies de matorral, como las jaras o el romero, podían ser restos del combustible utilizado.

La madera asociada a objetos metálicos es un documento excepcional. Durante el proceso de excavación se observó esa asociación pero pocos restos orgánicos ofrecían garantías. Sí hemos podido documentarla durante la restauración en el laboratorio. El estado de conservación es muy variable, desde restos parcialmente carbonizados hasta madera fresca y/o mineralizada, a veces con incrustaciones metálicas de la oxidación de las piezas, en cuyo caso resultó especialmente difícil la identificación botánica.

La importancia de identificar estas pequeñas muestras orgánicas reside en la posibilidad de documentar las maderas utilizadas para la elaboración de útiles, en estos casos, fundamentalmente armas y algunas piezas de construcción. Salvo en condiciones muy específicas (Carrión

\begin{tabular}{|l|c|c|c|c|}
\hline \multicolumn{1}{|c|}{ UUEE } & \multicolumn{2}{c|}{1075} & \multicolumn{2}{c|}{$\mathbf{1 0 6 6}$} \\
\hline \multicolumn{1}{|c|}{ Taxones } & $\mathbf{N}^{\mathbf{0}}$ & $\mathbf{\%}$ & $\mathbf{N}^{\mathbf{0}}$ & $\mathbf{\%}$ \\
\hline Cistus sp. & & & 1 & 0,373134328 \\
\hline Fraxinus sp. & 6 & 10 & & \\
\hline Leguminosa & 2 & 3,33 & & \\
\hline Pinus halepensis & 25 & 41,67 & 194 & 72,39 \\
\hline Pinus sp. & 1 & 1,67 & 25 & 9,33 \\
\hline Conífera & & & 3 & 1,12 \\
\hline Prunus sp. & 1 & 1,67 & 1 & 0,37 \\
\hline $\begin{array}{l}\text { Quercus } \\
\text { perennifolio }\end{array}$ & 22 & 36,67 & 37 & 13,81 \\
\hline Quercus sp. & 2 & 3,33 & 1 & 0,37 \\
\hline $\begin{array}{l}\text { Rosmarinus } \\
\text { officinalis }\end{array}$ & & & 2 & 0,75 \\
\hline Indeterminable & 1 & 1,67 & 4 & 1,49 \\
\hline Total & 60 & 100 & 268 & 100 \\
\hline
\end{tabular}

Tab. 1. Carbones sobre el suelo de la Puerta Oeste (UUEE 1066 y 1075). y Rosser 2010), esta información se pierde con la degradación natural de la madera. La tabla 2 muestra los resultados del análisis de estas maderas o carbones en relación a las piezas metálicas. Nos parece coherente el uso de madera de pino (y esporádicamente de carrasca) asociado a las pletinas y clavos, es decir, piezas de carpintería que son los elementos de gran calibre referidos arriba. Es llamativo que se emplee madera de sauce-chopo en sendos escudos hallados, o probablemente de madroño en una vaina, ya que son maderas escasas o ausentes en otros contextos del poblado, lo que reforzaría la idea de su uso específico para la elaboración de estos objetos.

Gran parte de los herrajes y los restos carbonizados de madera descritos pueden relacionarse con los batientes de la entrada (Fig. 3). La información recuperada sugiere que la entrada tendría dos hojas abatibles de $1,30 \mathrm{~m}$ de anchura cada una. No podemos determinar la altura de las hojas pero es probable que rondara entre 2,5 y $3 \mathrm{~m}$ de altura. La estructura estaría basada en módulos de madera de pino. Cada batiente tendría unas seis tablas verticales de $18 / 20 \mathrm{~cm}$ de anchura y $5 \mathrm{~cm}$ de grosor unidas con traviesas $(6,5 \mathrm{~cm}$ de anchura y 5 y $10 \mathrm{~cm}$ de grosor) solapadas en el interior mediante remaches de chapa romboidal, situadas a unos $27 \mathrm{~cm}$ de distancia, con la cabeza redonda al exterior y la chapa romboidal al interior. Las pletinas en U son reparaciones. Al menos en una se utilizó carrasca, una madera más resistente, como indica la madera oxidada identificada en una pletina $\left(n^{\circ} 47\right)$ y que, sin duda, es madera en contacto con la pieza, a diferencia de los carbones recuperados junto a la misma pletina y que son de pino (Tab. 2).

Embutido en el pavimento y entre los quiciales se documentó un tablón de pino de sección cuadrada de $15 \mathrm{~cm}$ de anchura ( $\left.{ }^{\circ} 43\right)$. Como no se han hallado restos de quicios metálicos, ni chumaceras o quiciales de piedra ni ningún otro elemento de articulación de las hojas, cabe pensar que los quicios estarían labrados en la madera del montante de la puerta (quizás de carrasca a juzgar por los carbones $n^{\circ} 45$ y 46) y girarían en gorroneras talladas en el tablón embutido en el pavimento. No tenemos datos acerca del sistema de cierre pues no han aparecido huellas de trancas ni en los muros ni en la roca que aflora en el suelo, pero es factible que hubiera algún tipo de tranca interior. 


\begin{tabular}{|c|c|c|c|c|c|c|c|c|c|c|c|c|c|c|c|c|c|c|c|c|}
\hline 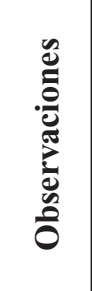 & 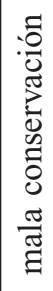 & & & 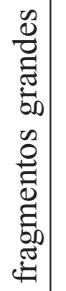 & 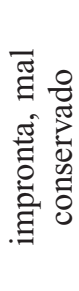 & & & & 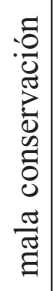 & 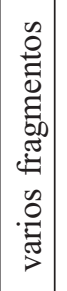 & 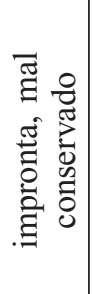 & 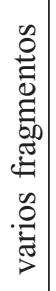 & & 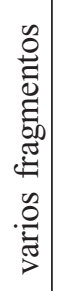 & 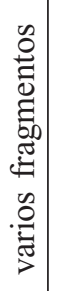 & & 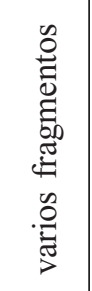 & 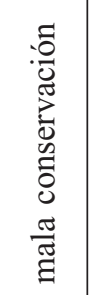 & & \\
\hline 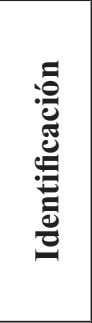 & 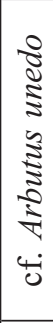 & 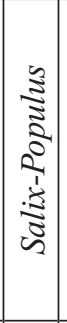 & 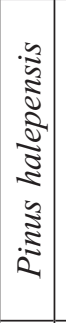 & 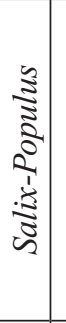 & 苞 & 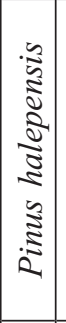 & 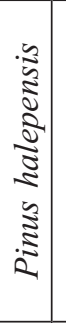 & 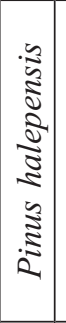 & $\begin{array}{c}\stackrel{\pi}{0} \\
\stackrel{\Xi}{0} \\
ن\end{array}$ & 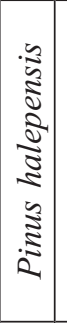 & $\begin{array}{l}\dot{2} \\
\vdots \\
\vdots \\
\vdots \\
\vdots \\
2\end{array}$ & 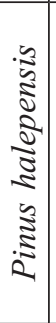 & 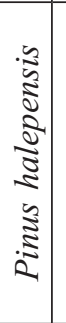 & 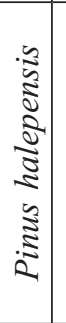 & 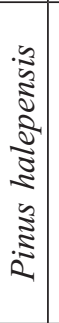 & 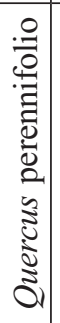 & 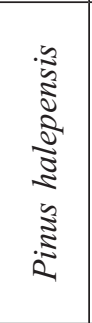 & $\underbrace{\stackrel{\Xi}{0}}_{\stackrel{\Xi}{0}}$ & 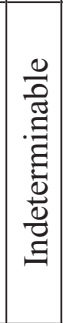 & 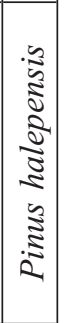 \\
\hline نُ & 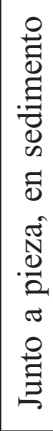 & 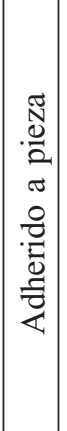 & 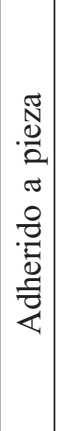 & 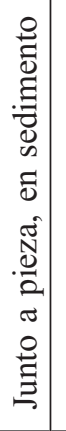 & 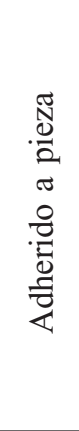 & 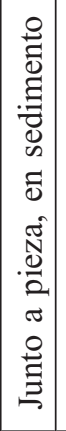 & 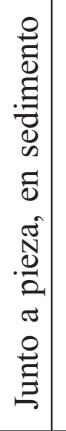 & 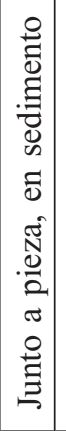 & 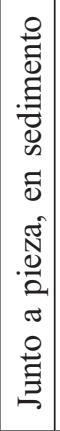 & 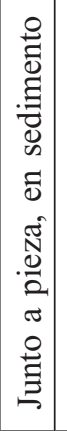 & 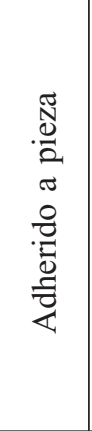 & 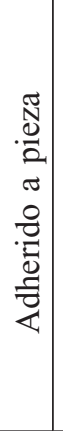 & 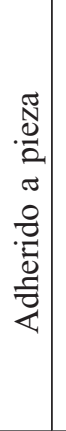 & 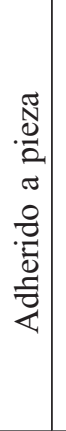 & 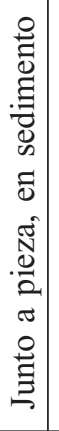 & 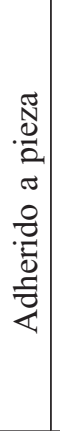 & 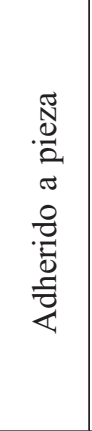 & 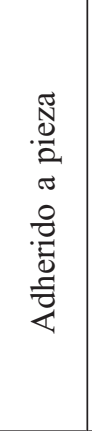 & 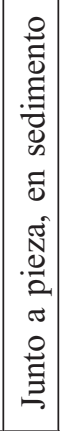 & 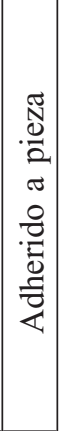 \\
\hline 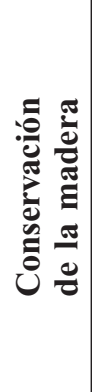 & 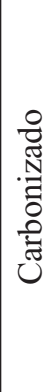 & 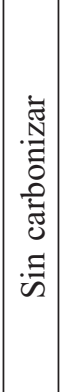 & 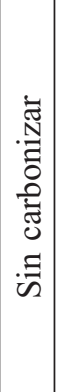 & 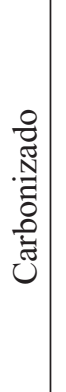 & 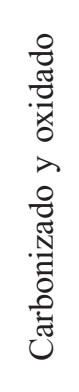 & 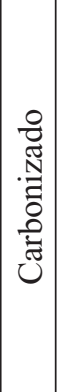 & 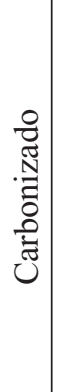 & 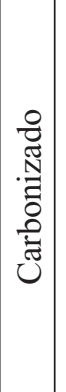 & 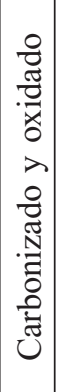 & 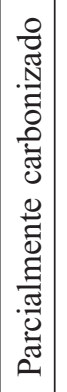 & 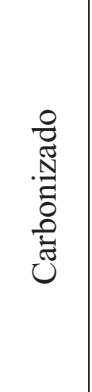 & 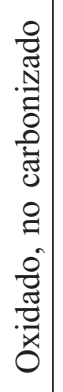 & 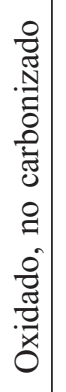 & 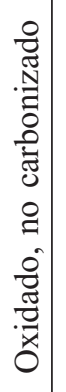 & 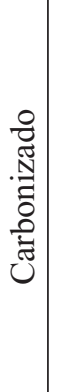 & 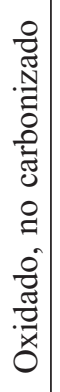 & 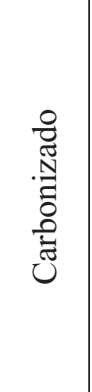 & 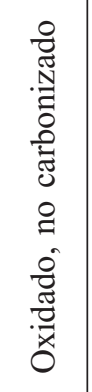 & 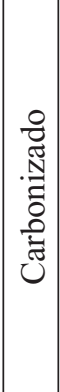 & 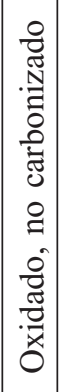 \\
\hline$\frac{\stackrel{0}{\circ}}{\frac{0}{0}}$ & 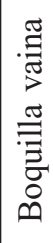 & 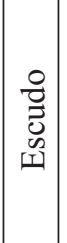 & 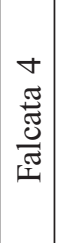 & $\begin{array}{l}0 \\
\overline{0} \\
0 \\
0 \\
0 \\
0 \\
0 \\
\tilde{E} \\
\Sigma\end{array}$ & 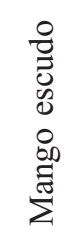 & $\mid \begin{array}{c}\vdots \\
0 \\
0 \\
0 \\
0 \\
0 \\
0 \\
0 \\
0\end{array}$ & 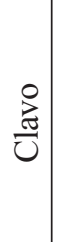 & 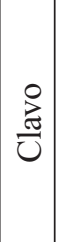 & 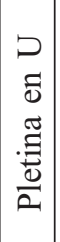 & 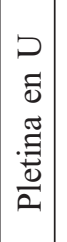 & $\begin{array}{l}D \\
\tilde{0} \\
\tilde{\Xi} \\
\stackrel{\Xi}{0} \\
\frac{0}{2}\end{array}$ & 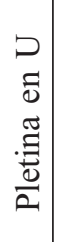 & $\begin{array}{l}\square \\
\tilde{\Xi} \\
\tilde{\Xi} \\
\stackrel{\Xi}{\Xi} \\
\frac{0}{2}\end{array}$ & $\begin{array}{l}\square \\
\tilde{\Xi} \\
\tilde{\Xi} \\
\stackrel{\Xi}{\Xi} \\
\underline{0}\end{array}$ & 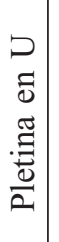 & 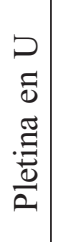 & 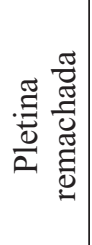 & 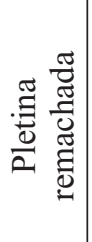 & 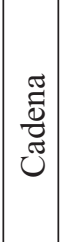 & 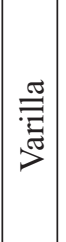 \\
\hline$\stackrel{\varrho}{\Xi}$ & 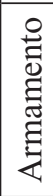 & 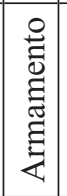 & 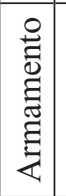 & 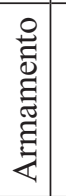 & 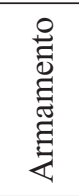 & 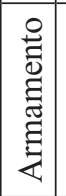 & 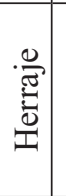 & 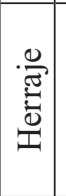 & 离 & 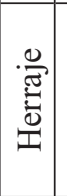 & 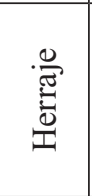 & 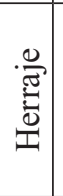 & $\begin{array}{l}\stackrel{0}{\mathbb{T}} \\
\stackrel{\vec{U}}{\mathbb{U}}\end{array}$ & 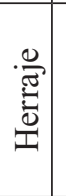 & 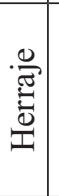 & 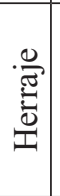 & $\begin{array}{l}\stackrel{0}{\pi} \\
\frac{\pi}{0} \\
\text { 蒠 }\end{array}$ & 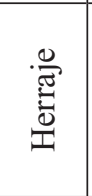 & $\stackrel{\dot{\Xi}}{\Xi}$ & 离 \\
\hline Z & $\stackrel{n}{=}$ & 志 & $\begin{array}{c}\infty \\
n \\
0 \\
\\
\end{array}$ & gे & g & 。 & $\infty$ & $\approx$ & $\stackrel{0}{-}$ & $=$ & I & Әे & ষे & ষా & 于 & 寸 & $\stackrel{\Re}{\forall}$ & สু & 0 & 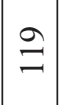 \\
\hline
\end{tabular}

Trab. Prehist., 72, N. ${ }^{\circ}$ 2, julio-diciembre 2015, pp. 282-303, ISSN: 0082-5638 


\subsection{Armas}

\subsubsection{Análisis tipológico de las armas}

Se han documentado falcatas, elementos de vaina, soliferrea, moharras de lanza/jabalina y regatones, elementos de escudo y cuchillo afalcatado.

Las falcatas son 5, todas completas (Fig. 5: 1, 8, 11, 15 y 16). Cuatro de ellas tienen empuñaduras del tipo A, cabeza de ave, variante 1 de Cuadrado (1989), y una del tipo B, cabeza de pseudocaballo, variante $2 \mathrm{c}$ de Cuadrado. Conservan los remaches para las cachas: discos planos con resaltes en las falcatas 27 y la 48 y en forma de estrella con lados cóncavos en la 31 y 33 . Ninguna falcata tiene restos visibles de decoración damasquinada. Excepto la falcata 33, están inutilizadas mediante plegado de los extremos distales (punta) y las hojas curvadas en ' $S$ ', unas de manera suave y otras más marcadas. La falcata 27 es la única que tiene un mellado sistemático del filo, al menos, en cinco puntos y la 31 tiene doblada intencionalmente la lámina plana de la empuñadura.

Las falcatas forman un lote muy homogéneo. $\mathrm{Si}$ tenemos en cuenta la extrema variabilidad en los tamaños, formas, orientaciones y detalles de las falcatas, resultado de su forja artesanal (Quesada 1997: 90; Quesada et al. 2000: 15), este lote, salvo quizá la falcata 31 , es tan próximo como para suponer que lo fabricó un mismo taller y en un margen de tiempo reducido. Solo la falcata 31 no se asocia a otras armas, y se separa del resto tipológicamente, ya que cuenta con guarda basal de barra maciza y tiene una empuñadura con cabeza de caballo, o de 'pseudocaballo'. Quizá sea el ejemplar más reciente del conjunto, dentro de su gran homogeneidad, o simplemente una versión de otro herrero contemporánea de las otras. La homogeneidad observada no quiere decir que necesariamente se forjaran pensando en su utilización en estos depósitos. Si atendemos a sus medidas, están en los valores medios del foco alicantino septentrional y valenciano meridional, que forman una unidad en cuanto a panoplia se refiere en comparación con lo que ocurre al norte de dicho curso fluvial (Quesada 1997: 32 y 622623). En conjunto, las falcatas de La Bastida se pueden datar casi con seguridad en la primera mitad del siglo IV a.C., y probablemente en torno a la parte más antigua de dicha horquilla.

Hay varios elementos de vaina de armazón metálico, con cañas de hierro dobladas en forma de 'U' y abrazaderas para sujetar cuerpos de vaina de espada y/o puñal de madera o cuero (Cuadrado 1989: 22-26 quien sólo considera el cuero; Quesada 1997: 105-107, Fig. 5: 17-21). En el conjunto 1 aparece al menos una abrazadera de segunda guarnición (parte media de la vaina, véase Cuadrado 1989) $(1066 / 75)$ y dos botones de cabeza hemiesférica muy aplanada (1066/73 y 74) (tipo 1 de Cuadrado 1989: Fig. 6), propios para abrochar la correa de suspensión de la falcata (tahalí) (Fig. 5: 4, 6 y 7). Junto al conjunto 2, pero ligeramente por encima (UE 1054/115, Fig. 5: 10), apareció otra pieza de vaina, en este caso una embocadura del tipo Cuadrado $1 \mathrm{~b}$, con un lado más alto que otro. En el conjunto 3 se recuperó un fragmento de primera o segunda guarnición de falcata (1066/64, Fig. 5: 13) ya que se aprecia la curvatura para el cuchillo afalcatado, pero no los extremos, donde reposarían una o dos anillas. El lote de piezas de vaina más sustanciales en tamaño está cerca de la falcata 31: fragmentos del armazón metálico, guarniciones y extremo distal $(1066 / 60,61,77$ y probablemente 135, Fig. 5: 17 y 19). Además de los restos asociados directamente a cuatro de las cinco falcatas, contamos con un lote de otras guarniciones de vaina. En conjunto, los elementos recuperados pertenecen a un mínimo de 3 vainas diferentes, y quizá hasta cinco. Sólo en los conjuntos 1 y 5 hay restos suficientes para pensar en que fueran vainas completas, quemadas y dañadas antes de la deposición. En los conjuntos 3 (con seguridad) y 2 (posiblemente) se hallaron piezas aisladas.

Junto con las falcatas, los soliferrea forman el lote más numeroso de armas (Fig. 5: 2 y 2225). Todos están cizallados y las puntas dobladas. La pieza más completa se asocia al conjunto 1 (1066/25 y 1066/140). Del conjunto 3 procede una punta de soliferreum o pilum (difícil de distinguir sin el arranque del cubo, $c f$. Quesada 1997: 309), doblado en ángulo (1066/70, Fig. 5: 14). El resto de los fragmentos asimilables a soliferrea proceden de la UE 1054 por lo que no se pueden asociar directamente a ninguno de los conjuntos, aunque alguno, muy cercano en el plano horizontal o vertical, pudo pertenecer a ellos (puntas 1054/89, 90, 98 y 1050/3, algunas con claros pa-

Trab. Prehist., 72, N. ${ }^{\circ}$ 2, julio-diciembre 2015, pp. 282-303, ISSN: 0082-5638

doi: $10.3989 /$ tp.2015.12155 

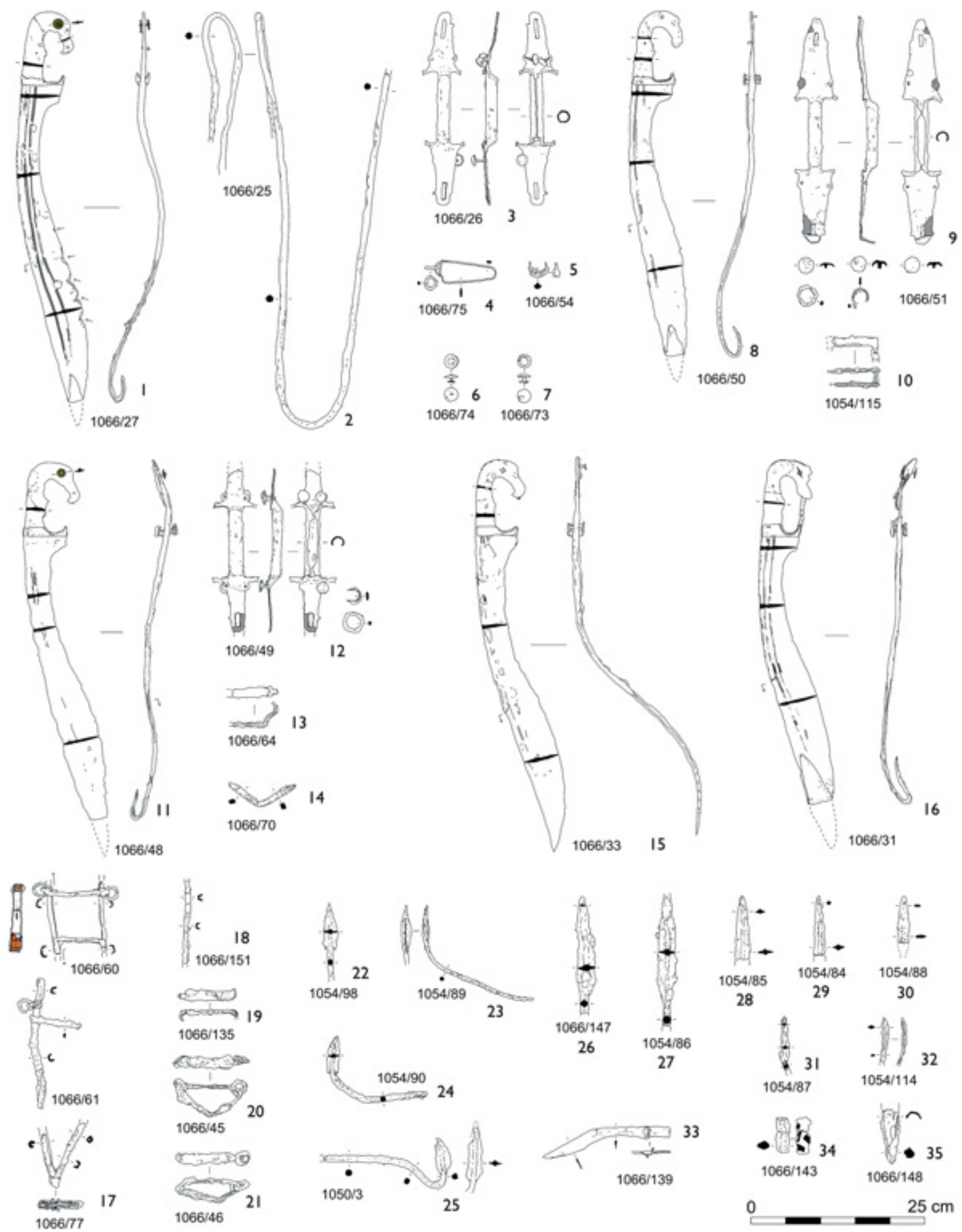

Fig. 5. Armas halladas en la Puerta Oeste. 1-7: conjunto 1; 8-10: conjunto 2; 11-14: conjunto 3; 15: falcata del conjunto 4; 16: falcata del conjunto 5 . El resto son armas sin atribución segura a conjuntos.

Trab. Prehist., 72, N. ${ }^{\circ}$ 2, julio-diciembre 2015, pp. 282-303, ISSN: 0082-5638 
ralelos en el poblado, Fig. 5: 22-25). Un segundo grupo de puntas tiene hojas de menor tamaño, quizá de soliferreum o quizá de pilum: 1054/87 y 1054/114 (Fig. 5: 31 y 32). Ambas son más cortas y sobre todo más estrechas que las anteriores.

Una categoría diferente de armas ofensivas de astil es la formada por lanzas y jabalinas (Fig. 5: 26-30). En el lote hay algunos fragmentos de punta que deben pertenecer a esta categoría. En contra de lo habitual ni conservan los cubos, ni siquiera sus arranques, lo que no debe ser casual. Por ello hay incertidumbre sobre la función de alguna de las piezas que pudiera pertenecer a la categoría de armas arrojadizas pesadas (soliferrea y pila) con moharras inusualmente grandes. Las puntas mayores son 1054/84, 85 y 86 y $1066 / 147$ (Fig. 5: 26-29) y el fragmento menor 1066/143 (Fig. 5: 34) que parecen formar un lote o serie de fabricación. Todas son puntas de nervio marcado circular (Tipo Quesada 1) o cuadrado (Tipo 2), con moharra variante VIB, la más común en el poblado. La punta 1054/88 (Fig. 5: 30) es más pequeña, propia de jabalina.

El regatón es el tipo más frecuente de objeto asociado a armamento en el oppidum (aunque véase Quesada 2010a: 207) pero en el conjunto sólo se ha documentado uno (1066/148, Fig. 5: $35)$, además exageradamente ancho, más de contera de bastón que de lanza.

Las 4 manillas para escudo circular (Fig. 5: 3, 9 y 12) se asocian significativamente a los cuatro primeros conjuntos, aunque una de ellas (1066/62 del conjunto 4) estaba por completo deshecha e irrecuperable. Las tres aletas completas, todas con dos puntos de sujeción y una apertura para la anilla soporte del telamon, son consistentes con una datación de la primera mitad del siglo IV (1066/26, 51 y 49) (Quesada 1997: 502 ss.) y su tipología está muy próxima a la de los escasos ejemplares encontrados en el interior del oppidum.

Es necesario por último mencionar un gran cuchillo afalcatado (1066/139, Fig. 5: 33) de casi $19 \mathrm{~cm}$ de longitud máxima. En nuestro contexto puede ser simplemente la 'navaja multiusos' que se embute en la vaina de las falcatas (Cuadrado 1989: 75-76). El tipo se relaciona con el mundo simbólico (Mancebo 2000; Ferrer y Casado 2014) y el ámbito del sacrificio o también como ofrenda (pequeñas falcatas-exvoto, Quesada 1997: 164168). Esta connotación no puede despreciarse en la Puerta Oeste, sobre todo a la vista de los otros materiales documentados que sugieren la presencia de ofrendas animales y vegetales.

\subsubsection{Los conjuntos de armas y su valoración global}

Las armas se agrupan en cinco conjuntos que forman lotes de llamativa similitud con ajuares funerarios ibéricos del sureste peninsular al sur del Júcar. Los elementos son coherentes entre sí, y lo primero que llama la atención es la homogeneidad basada en el trío espada + arma de astil + escudo. Es probable que algunos fragmentos y puntas de soliferrea correspondieran originalmente a los lotes identificados, pero sin una asociación directa o inmediata. Son panoplias funcionales aunque faltan las lanzas, habituales en las necrópolis. Compárese, por ejemplo, las armas documentadas aquí con la tabla general para 700 sepulturas ibéricas con armas (Quesada 1997: 644, fig. 350) y con el Cigarralejo, el principal conjunto unitario (Quesada 1998: 216, fig. 7). Pero también son lotes simbólicos, con un arma ofensiva personal y un arma defensiva como los únicos elementos constantes.

No estamos ante ofrendas simples donde un arma valga como pars pro toto que es lo más habitual: en 700 tumbas hay o una sola falcata $\left(\mathrm{n}^{\circ} 82,11,7 \%\right.$ del total) o un arma de astil $\left(\mathrm{n}^{\circ} 114\right.$, $16,4 \%$ ). Son más bien panoplias elaboradas y muy homogéneas entre sí: ninguna destaca jerárquicamente del resto por la presencia de armas de lujo, como puñales o cascos, o por la colocación de arreos de caballo. Volveremos al final sobre esta cuestión.

Las armas de este contexto son datables entre c. 400/350 a.C. Son comparables en su tipología, clase por clase y tipo por tipo (Quesada 2011) a las halladas en el interior del poblado, destruido violentamente quizá en el tercer cuarto del siglo IV a.C. (Bonet y Vives-Ferrándiz 2011: 254-255), aunque quizá algo más antiguas. Sin embargo, si comparamos las categorías de armas del interior del poblado con las de este lote (Fig. 6), vemos una notable diferencia en la composición porcentual por clases. Esa composición en las casas, patios y calles de la Bastida comparte con la de otros poblados ibéricos (Quesada 2010a) una baja

Trab. Prehist., 72, N. ${ }^{\circ}$ 2, julio-diciembre 2015, pp. 282-303, ISSN: 0082-5638

doi: $10.3989 /$ tp.2015.12155 

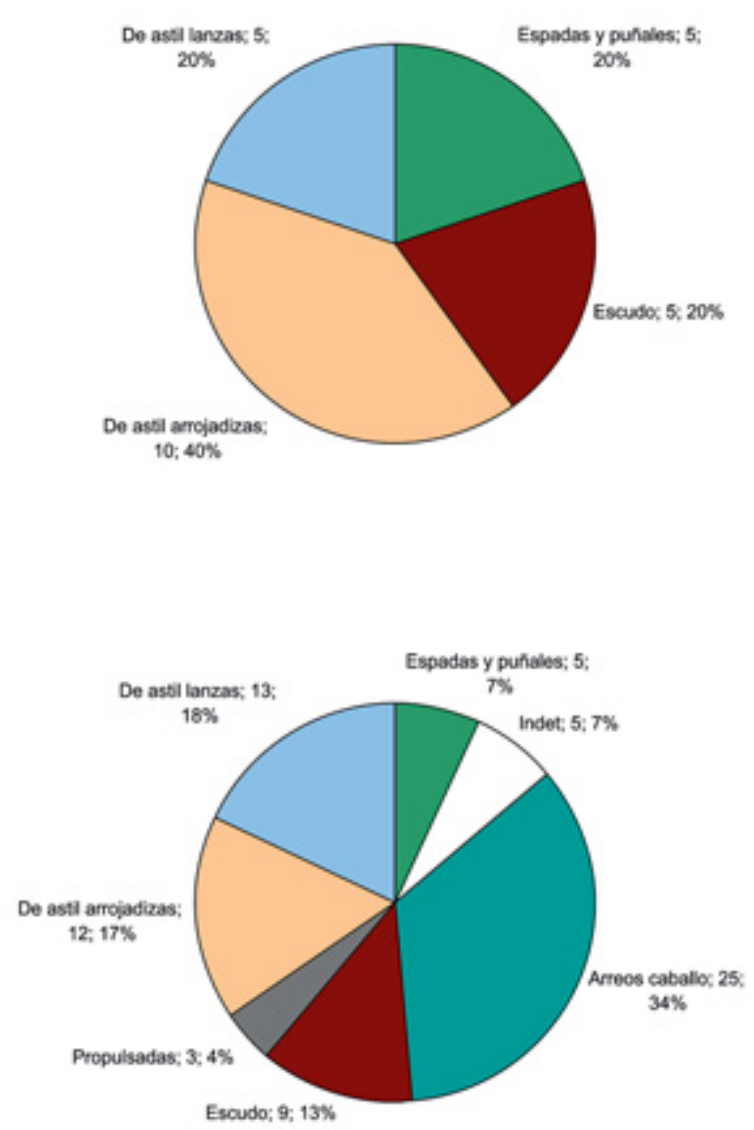

Fig. 6. Comparación entre las armas del ritual de la Puerta Oeste (arriba) y las del resto del poblado (abajo).

proporción de armas defensivas y de espadas, y una elevada proporción de armas de astil, arrojadizas o no, utilizables tanto en la caza como en la guerra (se detalla en Quesada 2011: 214-218). En cambio, la composición de las armas halladas en la Puerta Oeste se asemeja a la de los conjuntos de ajuares en necrópolis por su elevada proporción de espadas (armas ofensivas exclusivamente militares, y de costosa fabricación) y escudos, además de armas de astil de diversos tipos. Si nos fijáramos sólo en los cinco conjuntos definidos, la diferencia se hace aún más marcada.

\subsection{Cerámica}

Está muy fragmentada y dispersa por ambas unidades estratigráficas, aunque se concentra es- pecialmente en los cuadros ubicados entre los conjuntos 1, 4 y 5. Los 1118 fragmentos cerámicos recuperados no han permitido reconstruir ni un vaso. La cerámica fina o Clase A (638 fragmentos) es más frecuente que la de cocina o Clase B (459 fragmentos) y ambas están mucho más representadas que las importaciones (21 fragmentos). Estas últimas son siempre piezas de vajilla ática de barniz negro y figuras rojas. En la UE 1054 predomina la cerámica fina (349 fragmentos) sobre la de cocina (87) y las importaciones (19), mientras que en la UE 1066, sobre el suelo, la cerámica fina desciende a 289 fragmentos, aumenta considerablemente la de cocina con 272 y hay sólo dos fragmentos de la importada.

La tipología de las piezas ibéricas documenta formas ya conocidas en los contextos domésticos de la Bastida (Bonet y Vives-Ferrándiz 2011: 148165). Los recipientes cerrados de cerámica fina son 10 tinajas y tinajillas de pequeño y mediano tamaño, una de ellas con pico vertedor, 1 gran lebes y 1 botellita. Las formas abiertas son 4 bordes de páteras y escudillas y 1 plato de pescado. Como cerámica de cocina, hay 6 ollas, dos de ellas con pico vertedor, y 1 tonel. Sorprende la escasa presencia de grandes recipientes (ánforas, tinajas), de vasos de beber o de servir y la ausencia de morteros, microvasos, fusayolas o pesas de telar.

Las cerámicas directamente vinculadas a los conjuntos de armas son pocas y muy fragmentadas (Fig. 7). En el conjunto 1, el más completo en cuanto a armas se refiere, hay 2 ollas y 1 gran tejuelo, parcialmente quemado, depositado en el centro de la panoplia. En el conjunto 2 tenemos 1 borde de tinaja de cerámica fina, 1 gran fragmento de tonel de cerámica tosca y 2 tejuelos. En el conjunto 3 se hallaron fragmentos de un gran recipiente bajo la espada. El conjunto 4 sorprende con 7 tejuelos, uno de ellos de ánfora púnicoebusitana, 1 pico vertedor de cerámica tosca y 1 borde de lebes, quemado y fragmentado en 16 trozos que resulta ser la pieza más completa de todo el depósito. En el conjunto 5 se contabiliza 1 tejuelo, 2 bordes de tinajillas y 2 de olla y 1 pico vertedor también de cerámica tosca.

Hay 4 vasos áticos de barniz negro (un borde y un asa de dos copas diferentes, un borde de escifo y una base de pátera F. 25 Lamb.) y 2 cráteras de campana de figuras rojas que se fechan en el segundo cuarto del siglo IV a.C. En las cráteras se representan escenas dionisíacas: en una de ellas se 


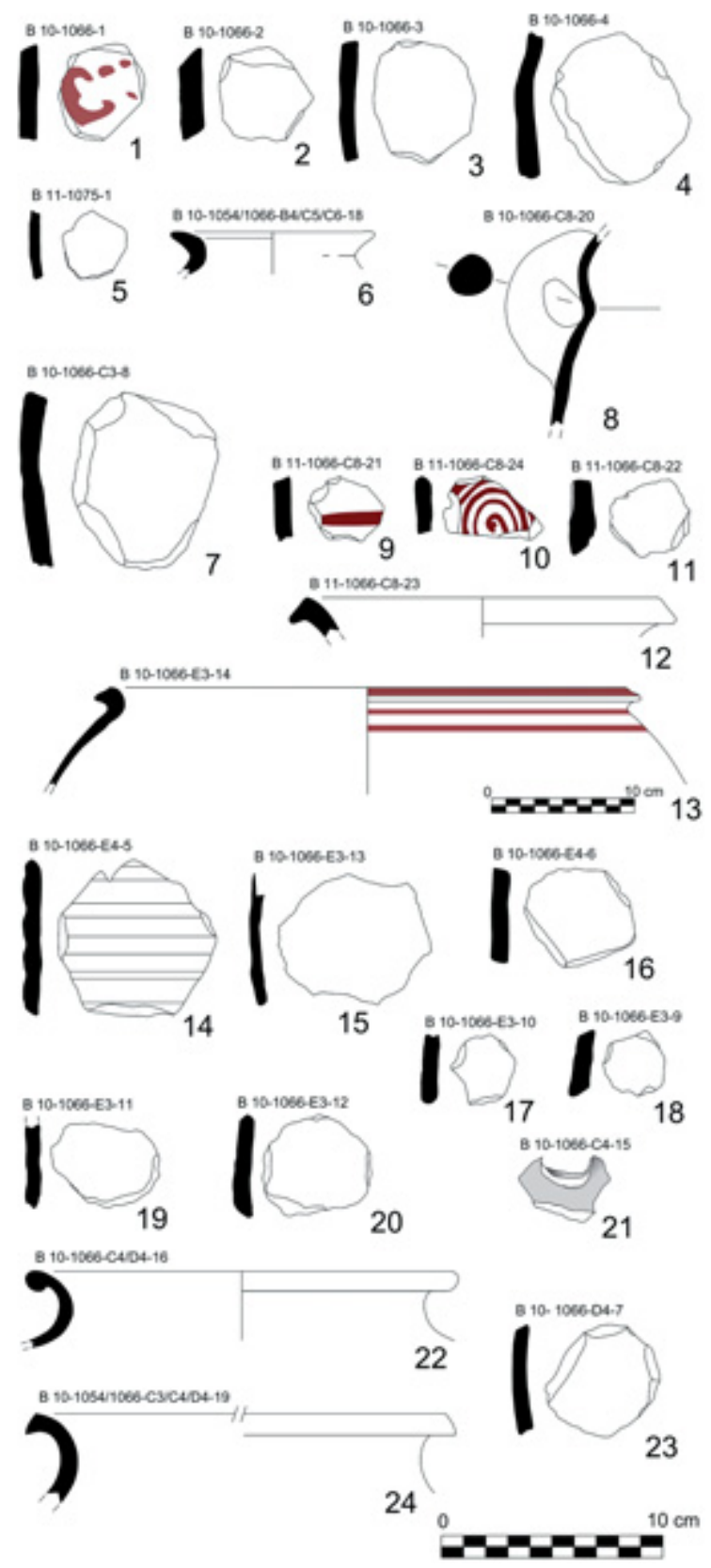

Fig. 7. Cerámica hallada en la UE 1066. 1-6: materiales sin atribución segura a conjuntos; 7: conjunto 1; 8-12: conjunto 2; 13-21: conjunto 4 ; 22-24: conjunto 5 .

ve un hombre y una mujer con restos de una piel (¿un sátiro? 1054-6, Fig. 8: 5) y en la otra hay una mujer y un sátiro con tirso en un fragmento y, en otro, un Eros y una cabeza femenina con el pelo recogido en una sphendóne, lo que es típico del pintor de Toya (1054 y 1066-25; Fig. 8: 6).
Los fragmentos de crátera aparecieron dispersos entre los conjuntos 3 y 5 .

Mención aparte merecen los 23 tejuelos de cerámica repartidos en las dos unidades estratigráficas (7 en UE 1054; 15 en UE 1066 y 1 en UE 1075, Fig. 7: 1-5, 7, 9-11, 14-20, 23). Trece son de cerámica fina, nueve de cerámica de cocina y uno de ánfora púnico-ebusitana. $\mathrm{Su}$ proporción varía en los cuatro conjuntos de procedencia: uno en el conjunto 1, otro en el 5, dos en el conjunto 2 y siete en el conjunto 4 . Los tejuelos se han interpretado como fichas de juego o pesos de telar y, sobre todo, como sistemas de cómputo pues aparecen formando series, en su mayoría en ámbito doméstico (Depto. 97 de la Bastida o Deptos. 42 y 73 del Tossal de Sant Miquel: Fletcher et al. 1969: 270; Bonet 1995: 182 y 215). Son escasos en las necrópolis pero también debieron tener alguna significación simbólica a juzgar por su depósito en contextos rituales como éste o como el depósito votivo con 18 ejemplares de El Amarejo (Bonete, Albacete, Broncano 1989: 107). Solo 3 de las 382 tumbas del Cigarralejo tienen tejuelos: 4 en la tumba 62 , uno en la 268 y otro en la 291, sin embargo se dice que son muy abundantes dentro y fuera de las tumbas (Cuadrado 1987: 102). En Coimbra de Barranco Ancho sólo los tienen 6 de las 160 sepulturas (García Cano et al. 2004).

\subsection{Semillas y frutos}

En el muestreo del sedimento se han recuperado restos de semillas y frutos. Todo el material está carbonizado pero no muy alterado, por lo que la temperatura osciló entre 200 y $250{ }^{\circ} \mathrm{C}$. Los taxones documentados no difieren de los reconocidos en las áreas de hábitat y basureros del resto del poblado. Destacan las cariópsides de trigos desnudos (Triticum aestivum-durum) y, en menor medida, de cebada vestida (Hordeum vulgare subsp. vulgare). Entre las leguminosas hay sobre todo vezas (Vicia sativa) y en menor media habas (Vicia faba) y entre los frutales higos (Ficus carica) y aceitunas (Olea europea). Las especies silvestres son escasas. Hay taxones que pueden desarrollarse como malas hierbas en los campos de cereales y otros de tipo arbustivo que debieron haber sido utilizados como combustible. 

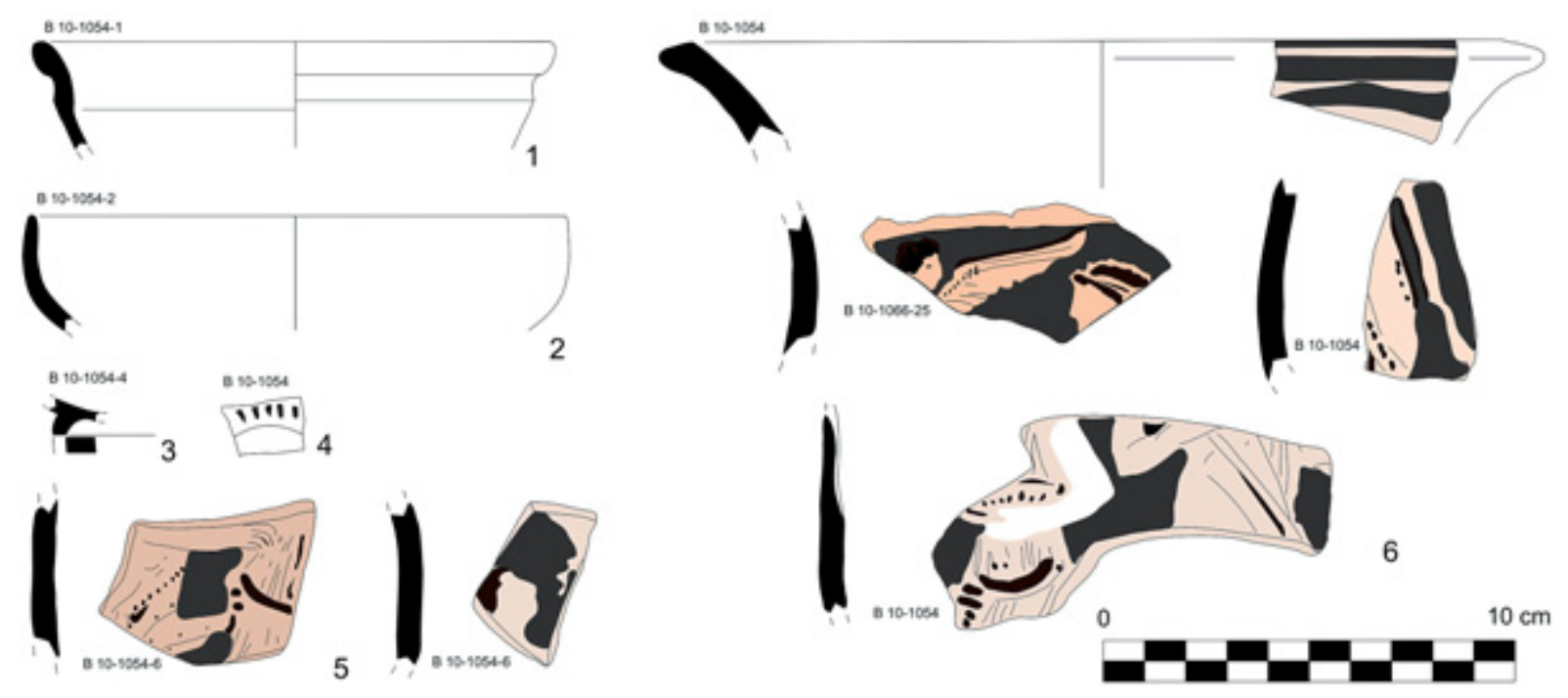

Fig. 8. Cerámica ática de barniz negro (1-4) y cráteras de campana de figuras rojas (5 y 6).

Los trigos desnudos representan más del 90\% de los restos.

El registro de este depósito y el del resto del poblado (Pérez Jordà et al. 2011) difiere en las frecuencias o número de restos de algunas especies y en los taxones presentes. Los cereales documentados son los que predominan en todas las áreas del poblado. La cebada vestida suele tener unos índices de frecuencia superiores pero en este caso se han seleccionado los trigos desnudos, sobre todo atendiendo al número de restos (Fig. 9). Una situación comparable respecto a las especies representadas y a sus proporciones se observa con las leguminosas y los frutos, salvo en el caso de la aceituna: hay más huesos en la Puerta Oeste que en todas las muestras del resto del poblado. Destaca la falta de uva, un frutal cuyos valores suele ser mayores o, en todo caso, comparables a los de los higos, en los contextos domésticos.

Las especies silvestres son difíciles de interpretar. Las de plantas de porte arbóreo o arbustivo como el lentisco (Pistacia lentiscus) y el enebro (Juniperus oxycedrus) podrían haberse empleado como combustible. Sin embargo, al no haberse documentado entre los carbones de este contexto (Tab. 1), ni aparecer con frecuencia los frutos de ambos taxones en el poblado, cabe pensar en un aporte intencional de los mismos, ambos de un llamativo color rojo. Los otros cuatro taxones identificados pueden ser malas hierbas que cre- cen entre los campos de cereales, pero Adonis sp. y Fallopia convulvulus faltan en los contextos excavados hasta la fecha en el yacimiento. La documentación de Adonis sp. por primera vez en el País Valenciano sería explicable no como algo accidental sino voluntario por su flor. En la misma planta suelen convivir flores abiertas con otras anteriores cuyas semillas han acabado de madurar. La segunda especie aparece asociada a conjuntos de cereales en poblados de la Edad del Bronce (2) con suelos arenosos en el entorno, caso de la Bastida de les Alcusses. No produce flores de gran tamaño sino en racimos, por lo que es razonable que su presencia sea accidental a diferencia de Adonis sp. Finalmente, la condición de Galium sp. y la gramínea como malas hierbas se refuerza por su asociación a concentraciones de trigo y cebada.

La distribución de los materiales (Fig. 9) en la UE 1066 no muestra diferencias entre el registro recuperado sobre el nivel donde estaban los depósitos, y el resto de este estrato. En cambio el estrato que lo cubre (UUEE 1050 y 1054) tiene una menor diversidad taxonómica y una densidad de restos muy inferior. En los materiales distribui-

(2) Pérez Jordà, G. 2013: La agricultura en el País Valenciano entre el VI y el I milenio a.C. Tesis Doctoral. Departament de Prehistòria i Arqueologia. Facultat de Geografia i Història. Universitat de València. València. 

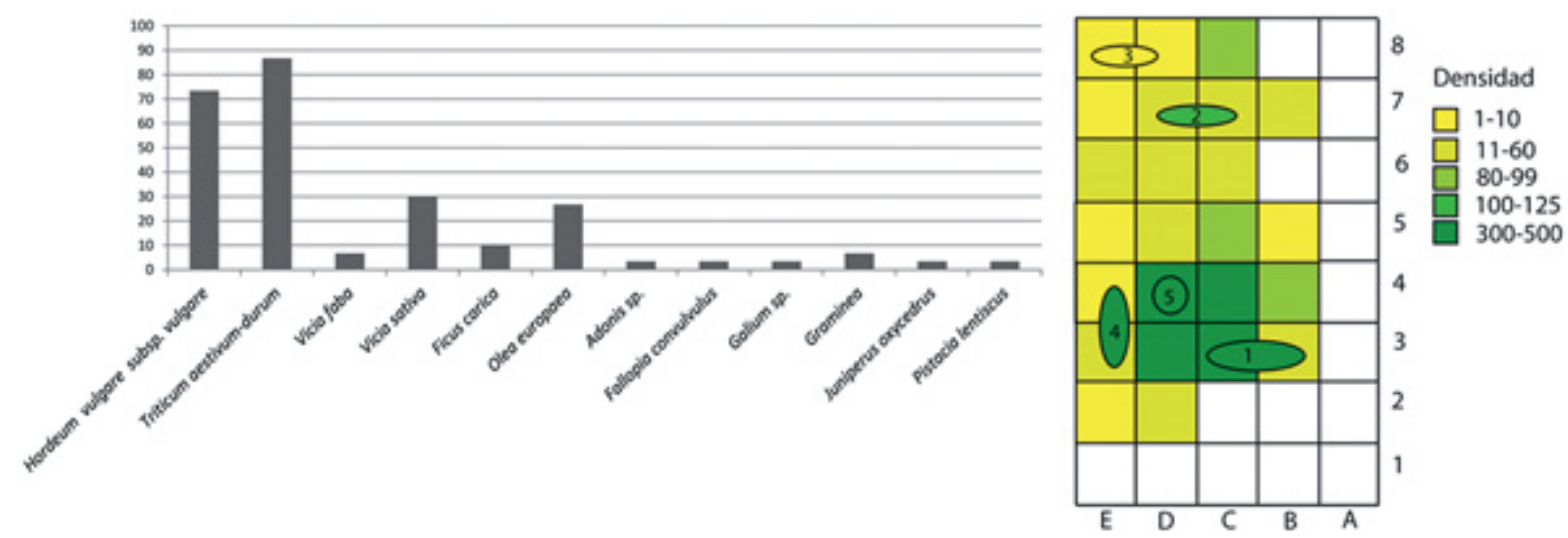

Fig. 9. Presencia de las especies de plantas identificadas en la Puerta Oeste. A la derecha, densidad y distribución de los restos.

dos directamente sobre el suelo no se observa una asociación directa entre las semillas y frutos y los conjuntos de armas. Los conjuntos de armas 2 y 4 son los únicos cuya densidad de restos supera la del cuadro donde se ubican. En los conjuntos 2, 3 y 4 el número de restos de semillas y frutos es equivalente en el cuadro y en el sedimento asociado al conjunto. En el 1 y 5 son más escasos. En general, los materiales (número de restos, densidad) están concentrados en el centro del área, en especial en los cuadros D-C/3-4, al margen de que tengan o no conjuntos de armas. No se puede concluir, por tanto, que los restos carpológicos se colocaran junto a las armas.

La composición taxonómica de los restos carpológicos es similar en los cinco conjuntos. Destacan los cereales, aunque en el 2 y el 3 el volumen de restos es muy escaso. El resto de taxones varían: las vezas se asocian a los conjuntos 2, 4 y 5; los higos son exclusivos del 4 y de su entorno; las aceitunas de los conjuntos 1 y 5 y de cuadros adyacentes, y solo hay lentisco en el 1 . Los dos taxones ausentes de estos depósitos pero presentes en alguno de los cuadros son Adonis sp. y el enebro. No hay casi diferencias entre los conjuntos y el material recuperado en los cuadros, más allá de los pocos taxones identificados sólo en algunas muestras (las habas en los cuadros C8 y D8). Parece observarse una distribución diferencial de los cereales. En la parte frontal de las filas 7 y 8 (cuadros y conjuntos) aumenta la cebada vestida, lo que equilibra este taxón, y los trigos desnudos. En las filas centrales de los cuadros, las 3, 4 y 5, el predominio de los trigos desnudos es muy relevante.

\subsection{Fauna}

Se ha analizado un conjunto de 102 huesos y sus fragmentos. Se ha determinado el 20,58\%. El resto $(79,41 \%)$ son astillas de entre 0,5 y 4 $\mathrm{cm}$ pertenecientes a huesos largos de mesomamíferos. Los taxones identificados son la oveja (Ovis aries), el ciervo (Cervus elaphus), el conejo (Oryctolagus cuniculus), malacofauna terrestre, un anfibio indeterminado y una costilla de micromamífero.

El estado de conservación del material es muy deficiente. En general muestra una seria afección debida al proceso de fosilización durante la fase postdeposicional, debida a la vegetación, los ácidos húmicos y el propio $\mathrm{Ph}$ del sedimento. Estas alteraciones se suman a las producidas durante el manejo de los restos óseos en las operaciones de cocinado y consumo antes de depositarse. Un fragmento de diáfisis de un hueso apendicular de mesomamífero muestra una marca de carnicería. En 4 restos hay evidencias de combustión: el fragmento lateral de un astrágalo de oveja totalmente calcinado y tres fragmentos de hueso largo, menores de $2 \mathrm{~cm}$ con extremos quemados de coloración marrón. Varía su respectivo grado de combustión.

Los ovicaprinos son el grupo de especies mejor representado aunque sus restos están muy 
fragmentados: 2 dientes sueltos, 3 fragmentos de diáfisis de húmero, 2 diáfisis de fémur, 1 diáfisis de tibia, 1 fragmento lateral de astrágalo, 1 fragmento de metapodio y 1 tercera falange. Hemos podido identificar tres restos de oveja: dos molares con desgaste propio de un ejemplar juvenil y un fragmento calcinado de astrágalo.

Se han identificado animales silvestres. De ciervo hay 7 fragmentos de un mismo metatarso izquierdo de una hembra o de un animal juvenil. $\mathrm{Su}$ gran afección cortical por la acción de los agentes edáficos impide observar marcas indicativas de su consumo. Hay un fragmento proximal de primera falange de conejo, una vértebra de anfibio, una costilla de un micromamífero indeterminado y cuatro caracoles terrestres.

El grupo de no identificados está formado por 79 fragmentos de huesos de animales de talla media y otros 2 de mayor complexión como los équidos (caballo/asno), los bovinos (vaca/toro) y el ciervo. En el grupo de mesomamíferos destacamos 3 restos quemados de entre 1 y $2,5 \mathrm{~cm}$ con algún extremo de color marrón. En el grupo de macromamíferos hay un fragmento de diáfisis de $9 \mathrm{~cm}$ cuyo grosor de paredes sugiere sea una tibia de un bovino o un équido $\left(\mathrm{n}^{\circ} 146\right)$.

El conjunto de restos óseos analizados del yacimiento procede principalmente de basureros y desperdicios alimenticios. En comparación con ese conjunto, el grado de fragmentación de los restos de la Puerta Oeste es mayor. También hay menos variedad de especies: una doméstica (la oveja) y dos silvestres (el conejo y el ciervo). Por número de restos ovejas y cabras son el principal grupo de especies en el poblado $(54,18 \%)$. El conejo y el ciervo son especies muy minoritarias $(2,69 \%$ y $0,5 \%$ respectivamente) (Pérez Jordà et al. 2011).

Los restos se distribuyen por los cuadros B, C, D y E con una mayor densidad alrededor del conjunto 5 (Fig. 2) pero su número es tan reducido que no podemos dar demasiada significación a este dato. El tipo de alteraciones que presentan sugiere que su historia tafonómica es heterogénea. Un grupo numeroso de fragmentos indeterminados, formado mayoritariamente por astillas de diáfisis de mesomamíferos con la cortical muy alterada y las aristas romas, podría ser material rodado. Esta tipología es frecuente en contextos de rellenos y su elevado grado de alteración habla de una exposición prolongada a los agentes de modificación. Podrían ser restos integrados en el sedimento y ajenos a los materiales depositados durante el ritual. Cuatro tienen señales de combustión en diferente grado: un fragmento de astrágalo calcinado $\left(600-800{ }^{\circ} \mathrm{C}\right)$ y tres de diáfisis quemados con coloración marrón negruzca (230$300{ }^{\circ} \mathrm{C}$ ). Como marcas de carnicería solo hemos identificado un corte sobre un fragmento de $2 \mathrm{~cm}$ (UE 1066-C2). Este hueso con marcas, los huesos de ovicaprino así como los restos alterados por una combustión podrían formar parte del conjunto de material relacionado con los desperdicios de un asado. La identificación de huesos calcinados y quemados, quizás generados durante una comida, se constata también en otros contextos rituales (Iborra 2012, 2014).

\subsection{Elementos de barro y conglomerado}

Se han estudiado 10 muestras de visu con ayuda de la lupa binocular. Cuatro son cantos de conglomerado y calcita y seis son fragmentos de barro. Estos últimos constituyen un variado conjunto de tipologías asociadas a elementos constructivos según un modelo propuesto previamente (Ferrer García 2010). Son fragmentos de enlucidos (muestra 189091), parte de posibles enfoscados y adobes (muestras 189079 y 189090), acabados de bancos u hornos (189089) y posibles elementos decorativos de barro moldeado (muestra 189092 y una pieza de barro completa recuperada en un testigo junto a unas maderas). Proceden de margas beige terciarias, arenas silíceas y formaciones edáficas pleistocenas que afloran en torno al yacimiento, junto con cantos y gravas de las propias laderas del promontorio de la Bastida. Las muestras están termoalteradas, formando agregados resistentes. Los interpretamos como resultado de una combustión somera (menos de $300{ }^{\circ} \mathrm{C}$ ) que al movilizar el carbonato cálcico consolida el sedimento, sin alterar apenas sus rasgos cromáticos (March 1995). Los posibles elementos decorativos poseen dos tonos a partir de una misma litología y textura, uno beige-ocre y otro gris oscuro, resultado de unas condiciones de combustión con diferente aireación.

Los cantos son fragmentos de conglomerados con bordes angulosos y cristales de calcita. Proceden de antiguas formaciones sedimentarias de 
ladera poco potentes, costras detríticas que afloran en el mismo promontorio. Tres (189082 y 189080 UE 1054; 189092 UE 1066) tienen una fina costra en una cara, indicativa de que se han desprendido de niveles superficiales. La mayor parte de un cuarto (189088 UE 1054) es un cristal de calcita. Todos evidencian una termoalteración muy intensa. Los cristales de calcita parecen ahumados, lo que exigiría una temperatura de más de $500{ }^{\circ} \mathrm{C}$ (Soler 2003). Los limos están rubefactados y los cantos que engloban están muy alterados, sin llegar a calcinarse. Ello indicaría que la temperatura no superó los 800 a $1000{ }^{\circ} \mathrm{C}$ (Karkanas 2007).

\subsection{Herramientas}

Identificamos dos útiles de herrero o yunques de pequeñas dimensiones. El primero (1054-127, Fig. 3: 8) es una pieza maciza de hierro de forma troncocónica con rebabas y evidencias de golpe en su cara más ancha, su plano de percusión. Posiblemente iría incrustado en algún pie de madera. El segundo útil apareció en el conjunto 1 (1066/28, Fig. 3: 9). Es una placa de hierro de forma rectangular algo trapezoidal con un agujero central. El lado ancho debió funcionar como plano de percusión, pues hay rebabas de golpes. Como la pieza anterior sería un pequeño yunque o una herramienta de percusión indirecta, como un encajador de carpintero o un cortafrío. No parece casual que se hallara junto a la falcata 27 que tiene la hoja mellada con varios golpes, quizás realizados con este objeto.

\subsection{Otros objetos}

Hay dos cuentas de pasta vítrea fragmentadas. Una es una cuenta de ojos (UE 1066-D7, Fig. 3: 11) de color azul con los ojos formados por puntos azules rodeados de puntos blancos, tipo que se documenta por primera vez en la Bastida. La otra tiene gallones verticales de color azul marino (UE 1054-142, Fig. 3: 10).

También se han recuperado varios fragmentos muy mal conservados de un posible rallador, una lámina de bronce con perforaciones (UE 1054124, Fig. 3: 12). Piezas similares proceden de contextos domésticos del propio yacimiento (departamento 80, Fletcher et al. 1969: 190, no 52) y de la tumba 200 del Cigarralejo (Cuadrado 1987: 371, Fig. 143).

\section{LA SECUENCIA RITUAL}

Las características del conjunto excavado, el tipo de materiales, su tratamiento y la deposición final y amortización conforman los restos físicos de un complejo ritual. Las secuencias de actuaciones implicaron elementos con enorme relevancia social como la puerta principal del oppidum, las armas de personajes de alto estatus, los restos de comida y la vajilla de importación. Con los datos disponibles podemos precisar que el ritual ocurrió hacia el segundo cuarto del siglo IV a.C. durante el verano, como indican la estación de corte de la madera y las semillas y frutos de lentisco, enebro y Adonis sp.

Las unidades estratigráficas distinguidas en la excavación (1054 y 1066) son inseparables a la hora de interpretar el conjunto, como demuestran por ejemplo los fragmentos de un mismo vaso cerámico presentes en ambas unidades. No parece que la deposición de los objetos siguiera un orden establecido: por ejemplo, en el conjunto 1 hay dos remaches (1066/24 y 72) bajo todas las armas, mientras en el conjunto 4 hay tablones quemados con remaches cubriendo la falcata $\left(n^{\circ} 11\right.$ y 12$)$. La cerámica está cubierta por armas en el conjunto 1 o 3 pero cubre a las armas en el 4. La gran formalidad en la deposición de armas, fragmentos cerámicos y herrajes, colocados en conjuntos sobre el suelo de la entrada, refuerza la simbología de la actuación ritual. En el conjunto 3 la manilla y la espada se colocaron juntas y paralelas entre sí, algo muy habitual en las necrópolis ibéricas, como Cabecico del Tesoro, Cigarralejo o Jumilla. Lo más llamativo es la colocación de manilla de escudo y espada en ángulo recto, formando una cruz (conjuntos 1, 2 y 4), lo que implica que previamente su cuerpo de madera había desaparecido o se había arrancado o quemado. La distribución específica de restos de fauna, frutos y semillas, herrajes y cerámicas por el suelo de la entrada también es intencional. Luego se cubrieron rápidamente con un paquete de restos quemados en una pira junto con tierra, elementos de cons- 
trucción y otros objetos incluidos en un material de relleno diverso. Sólo así se explica que haya fragmentos de fauna muy rodados o metales muy fragmentados como el resto de llanta de carro o las anillas y fragmentos de herrajes.

De entrada, sorprende que absolutamente 'todos' los objetos fueran alterados o destruidos mediante diferentes tratamientos como el fuego, la fragmentación o la inutilización. Cremación y rotura caracterizan muchas acciones rituales en objetos (Bradley 2005: 142 y 151) pero no son universales. En muchas cosmogonías el fuego es un elemento transformador de la sustancia. Aquí hemos identificado, al menos, dos cremaciones de distinta intensidad. Se hizo fuego en la misma entrada como indican el umbral de madera y piedras quemados y los elementos constructivos de barro termoalterados in situ. Como las muestras de barro moldeado están afectadas de manera desigual, el fuego de unos $300{ }^{\circ} \mathrm{C}$ que las alteró se produjo cuando formaban parte de estructuras. Otra cremación a $700-1000{ }^{\circ} \mathrm{C}$ tuvo lugar en el promontorio, quizás no lejos de la misma entrada. Afectó intensamente a elementos labrados de madera de la puerta, con herrajes incluidos, a algunos restos de fauna y cerámicas. No podemos precisar si los restos menores de madera carbonizada (Tab. 1) están in situ y son parte del combustible utilizado en esta pira o en el otro fuego. Evidencias indirectas de esta gran pira son los cantos quemados del suelo rocoso natural, incorporados con otros materiales, al paquete de amortización del depósito sobre el suelo. Debido a ello las maderas de gran tamaño quedaron fragmentadas y mezcladas con tierra y con el resto de materiales.

Las semillas y huesos de fauna, quemados a unos $200-300{ }^{\circ} \mathrm{C}$, pudieran proceder de una parte de la pira donde la temperatura no fue muy elevada o de otros fuegos menos intensos de documentación insegura. Otros objetos se depositaron sin quemar o apenas afectados por el fuego como algunos tablones de madera, quemados en parte, y otros remachados degradados por completo, a juzgar por algunas alineaciones de remaches sobre el suelo. Las armas, las cráteras de figuras rojas, algunos tejuelos cerámicos e incluso un resto de ciervo no están quemados. Los pequeños restos de madera fresca documentados en algunas piezas (Tab. 2) podrían indicar que la madera se mineralizó después, durante el proceso de oxidación del metal.
El grado de fragmentación depende del tipo de objeto. La cerámica y la fauna aparecen muy fragmentadas pero otros objetos no. El 98\% de los fragmentos cerámicos es inferior a $10 \mathrm{~cm}$ y el $36 \%$ a $3 \mathrm{~cm}$. Las lanzas y las vainas se rompieron. Las espadas se depositaron enteras pero con las hojas alteradas. Los mangos de escudo se depositaron enteros pero arrancados de su cuerpo de madera. Diferentes partes del mismo objeto están representadas desigualmente. En las vainas, lo que más falta son trozos de las varillas plegadas en ' $u$ ' del armazón. Estas ausencias son consistentes con (a) la deposición de elementos rotos de la vaina como pars pro toto; (b) una previa cremación a alta temperatura de los objetos que destruyera los elementos más frágiles y los perecederos; o (c) una combinación de ambas, en un ritual bien definido realizado a corta distancia pero no in situ. Sólo hallamos la punta de las lanzas y soliferrea. Sorprende la ausencia de conteras en unas y de las varillas del astil en los otros que llegan a medir unos $200 \mathrm{~cm}$ (Quesada 1997: 310). Si en el ritual se emplearon como mínimo hasta seis soliferrea, y quizá incluso nueve, no se depositaron completos (doblados o no, rotos o no) en el área excavada. Este hecho no es explicable por la durabilidad o conservación de las partes dado que hay piezas más frágiles conservadas. Una interpretación plausible es que cada parte del arma tuviera su propio significado a la hora de su deposición.

En la secuencia ritual también hubo actos de comensalía, constatada en la fauna con marcas de consumo y cocinado y en instrumentos como las ollas o el rallador para la preparación. La connotación sacrificial de las falcatas y del cuchillo afalcatado no debe ignorarse (Quesada 1997: 162-171), pues son usos complementarios y no excluyentes con su carácter de armas. El resto casi completo de metatarso de ciervo, una especie minoritaria en el poblado y presente en un conjunto de fauna tan reducido, debe tener un significado simbólico. Restos de ciervo se han identificado en algunos contextos rituales de yacimientos del País Valenciano (Iborra 2004: 367). Las semillas $\mathrm{y}$ frutos pudieron ser asimismo alimentos y ofrendas. A excepción de Adonis sp., todas las especies ya se conocían en los contextos domésticos del asentamiento. Las diferencias residen en una cierta selección de los trigos desnudos, un peso más relevante de las aceitunas y la ausencia de la uva. 
A modo de hipótesis, planteamos que ofrendas vegetales, como los frutos del lentisco y el enebro y las flores de Adonis sp., se seleccionaran por sus llamativos colores,

En síntesis, se utilizaron alimentos y artefactos cotidianos si bien imbuidos de énfasis y especial significación, como en muchos otros actos de ritualización (Bradley 2005: 119). Por ejemplo, el rallador podría relacionarse con la preparación de bebidas como la descrita en La Ilíada (XI, 638-641) donde se mezcla vino, harina y queso de cabra rallado. Esta práctica también se ha identificado en rituales funerarios itálicos en el siglo VII a.C. (Ridgway 1997) y quizás tuvo un alcance mediterráneo duradero en el tiempo. La comida estuvo limitada a un reducido número de personas, dado que la vajilla no supera los diez ejemplares, entre copas y platos, y hay pocos restos de animales procesados.

Algunas de estas actuaciones rituales exigieron trabajos precisos y experimentados de artesanos y especialistas vinculados a las élites: herreros para inutilizar las armas, carpinteros para desmontar la puerta y personas con experiencia para procesar animales, preparar comida y bebida o controlar los procesos pirotecnológicos que requieren las cremaciones. El trabajo de los herreros debió tener un especial significado, pues los dos pequeños yunques se incluyeron en las ofrendas.

\section{UN RITUAL PÚBLICOY SU SIGNIFICADO POLÍTICO}

La relevancia de este contexto para nuestro conocimiento de las sociedades de la Edad del Hierro radica, en primer lugar, en su escala y dimensión pública. El ritual tiene lugar en la puerta principal del oppidum, un espacio público de enorme relevancia para la identidad de la comunidad. Ocurre en un momento de reconstrucción de la entrada y la muralla que fechamos entre 375350 a.C. Los fragmentos de barro recuperados coinciden en sus rasgos morfológicos y texturales con elementos constructivos, tales como adobes, enlucidos, encalados, enfoscados y elementos decorativos, quizás de la propia entrada. Esta ceremonia pública que sanciona un acto de regeneración de estas construcciones también puede verse como uno de transformación por fuego. Re- cordemos que los mismos batientes de la entrada fueron desmontados, quemados y enterrados con los demás objetos (Fig. 3). Además es un ritual de memoria, pues toda el área del depósito se señalizó con tres losas y dos piedras hincadas, visibles cada vez que se pasaba por la nueva entrada (Díes 2005: 74, Fig. 2). Es decir, la entrada principal se utilizó como escenario para construir la memoria colectiva del grupo que habitaba el oppidum. En el oppidum de Burriac pasa algo parecido en el siglo II a.C.: bajo una de las piedras del enlosado de la entrada meridional, y asociado a su refacción, se halló una espada de tipo La Tène doblada en $\mathrm{V}$ en su vaina de hierro y quemada, así como restos de un ovicaprino (García et al. 1998: 313 y 323). Otros ejemplos de depósitos rituales en puertas y murallas, sin armas pero con restos animales, como en el Molón (Lorrio et al. 2014: 221, de nuevo asociado a una renovación de la muralla) o en el Cabezo de Azaila (Alfayé 2007), pueden leerse en esta línea de rituales de memoria colectiva. Los restos carpológicos en rituales fuera de necrópolis no se han documentado hasta la fecha.

Otro aspecto destacable es la violencia implícita que sugiere la deposición de las armas y el protagonismo ideológico de los asuntos de la élite guerrera en la sanción de los ciclos vitales del oppidum, así como de nuevas situaciones políticas y sociales. La inutilización de las armas reproduce claramente el tratamiento que conocemos en las tumbas y en contextos rituales no funerarios, como el ya referido de Burriac, el depósito de una falcata junto a otros hierros y bronces tras el templo B de la Illeta dels Banyets (Olcina et al. 2009: 135) o el soliferreum doblado ritualmente en el patio de entrada de Cancho Roano antes de su abandono (Kurz 2003: 301).

En la Puerta Oeste podemos excluir que estemos ante tumbas de personas, pues durante la excavación no se halló ni un solo resto humano. No obstante, hay estrechos paralelos con los rituales funerarios como el tratamiento de las armas, el uso del fuego para cremar ofrendas o la señalización mnémica con losas y estelas del depósito (visibles en la segunda fase de la puerta). Un contexto muy parecido a éste, por el volumen de armas hallado, es la célebre tumba 155 de la necrópolis de Baza (Granada), donde 19 armas se agrupan en cuatro panoplias completas en el ajuar funerario de una mujer (Quesada 2010b). 
El significado de las armas como símbolos de autoridad prestigiosa guerrera y política entre los guerreros ibéricos -hombres libres con un estatus significativo en tanto que tales- nos lleva a concluir que quizás representen a cinco grupos de poder, encarnados en la figura de cabezas de familia o de grupos corporativos. Esta interpretación no se contradice con la organización social de las casas en el oppidum (Vives-Ferrándiz 2013). En definitiva, es una actuación colectiva de la élite y no tanto la acción de un personaje poderoso con sus grupos clientelares dependientes. Con todo, las diferencias en la composición de cada panoplia y en el modo como se depositaron indican, precisamente, la heterogeneidad de la élite que cooperó en la celebración. Una acción colectiva de este carácter invita a pensar que el oppidum se rigió por relaciones sociales colaborativas y por acuerdos entre los cinco grupos representados por las cinco panoplias con derecho a tener un papel político y ser representativos de la comunidad.

\section{A MODO DE CONCLUSIONES}

El conjunto excavado en la Puerta Oeste de la Bastida de les Alcusses es una significativa novedad arqueológica. Apenas conocemos casos similares bien documentados en el ámbito ibérico y ninguno tiene su complejidad. El estudio interdisciplinar nos ha permitido identificar los restos de un ritual importante que, en torno al 375-350 a.C., conmemoró la renovación de la entrada principal y de las estructuras defensivas del oppidum. Como primera conclusión este trabajo reivindica los equipos y estudios multidisciplinares como vía para una mejor comprensión del registro arqueológico, complejo y variado por definición. Los materiales estudiados (herrajes, madera, armas, cerámica, semillas, frutos, fauna, elementos constructivos y herramientas...), junto a un detallado registro estratigráfico durante la excavación, nos han aportado información relevante para la comprensión de este contexto. El ritual se nos revela como secuencias de actuaciones y prácticas con un efecto material reconocible. En este caso incluye el desmonte de las estructuras de la puerta, la construcción de una pira para cremaciones rituales, actos de comen- salía, la destrucción ritualizada de los objetos por fragmentación o incineración y su deposición formalizada.

Este hallazgo nos sugiere varias reflexiones en el contexto de la Edad del Hierro en la Península Ibérica. Por un lado, resaltamos el significado social de ciertos espacios públicos, como la entrada principal, sobre todo para construir memoria a través de rituales bajo el control de las élites urbanas. Por otro lado, ciertas prácticas reconocidas hasta ahora en los rituales funerarios (cremación, inutilización de armamento) sin duda permearon otros contextos fuera de las necrópolis, lo que abre una vía de trabajo sobre las relaciones entre el mundo de los vivos y los muertos. Finalmente este ritual implica, en última instancia, la acción colectiva de una élite que obliga a replantear algunos de los paradigmas establecidos sobre la estructura social y la distribución del poder en las sociedades ibéricas.

\section{AGRADECIMIENTOS}

Las investigaciones en la Bastida de les Alcusses tuvieron el apoyo financiero del Museu de Prehistòria de la Diputación de Valencia. Se enmarcan en parte en el proyecto HAR2008/0435. En 2013 contaron con una ayuda a la investigación de la Mediterranean Archaeological Trust (Oxford). El artículo resume varios años de trabajo en cuyas diferentes etapas han participado Josep Ahuir, Gonzalo Almela, Iván Amorós, Aurora Bellver, Laia Caballer, Isabel Ferrándiz, $\mathrm{M}^{\mathrm{a}}$ Isabel Fuentes, $\mathrm{M}^{\mathrm{a}}$ Consuelo Laguna, Mireia López, Sonia Machause, Raúl Navas, Trinidad Pasíes, $\mathrm{M}^{\mathrm{a}}$ Amparo Peiró, Sergio Peral, María Perales, Pedro Ramos, Tamara Renau, José Manuel Torregrosa y Alicia Vendrell. Guillermo Tortajada y Alicia Vendrell dibujaron los materiales. Carmen Sánchez Fernández nos ayudó en la identificación de las escenas de las cráteras y nos puso sobre la pista de los paralelos con el pintor de Toya.

\section{BIBLIOGRAFÍA}

Alfayé, S. 2007: "Rituales relacionados con las murallas en el mundo celtíbero". Palaeohispania 7: 9-41. 
Bonet, H. 1995: El Tossal de Sant Miquel de Llíria. La antigua Edeta y su territorio. Diputación Provincial de Valencia. Valencia.

Bonet, H. y Vives-Ferrándiz, J. 2011: La Bastida de les Alcusses. 1928-2010. Diputación Provincial de Valencia. Valencia.

Bradley, R. 2005: Ritual and domestic life in Prehistoric Europe. Routledge. Londres.

Broncano, S. 1989: El depósito votivo ibérico de El Amarejo. Bonete (Albacete). Excavaciones Arqueológicas en España 156, Instituto de Conservación y Restauración de Bienes Culturales. Madrid.

Carrión, Y. y Rosser, P. 2010: "Revealing Iberian woodcraft: conserved wooden artefacts from south-east Spain". Antiquity 84, 325: 747-764.

Cuadrado, E. 1987: La necrópolis ibérica de El Cigarralejo (Mula, Murcia). Bibliotheca Praehistorica Hispana XXIII. CSIC Madrid.

Cuadrado, E. 1989: La panoplia ibérica de 'El Cigarralejo' (Mula, Murcia). Editora Regional de Murcia, Documentos, Serie Arqueología. Murcia.

Díes, E. 2005: "La Torre Portal y el Portal Torreado en las fortificaciones ibéricas. Estudio de las entradas Norte y Oeste de la Bastida de les Alcusses (Moixent, València). Saguntum 37: 73-84.

Ferrer García, C. 2010: "Los adobes y la arquitectura del barro en la Bastida de les Alcusses (Moixent, Valencia). Una aproximación desde el análisis sedimentológico". Archivo de Prehistoria Levantina XXVIII: 273-300.

Ferrer, E. y Casado, M. 2014: "Los cuchillos de hoja curva de hierro". En A. Fernández, A. Rodríguez, M. Casado y E. Prados (eds.): La necrópolis de época tartésica de la Angorrilla (Alcalá del Río, Sevilla). Universidad de Sevilla. Sevilla: 379-391.

Fletcher, D.; Pla, E. y Alcácer, J. 1969: La Bastida de les Alcuses II (Mogente - Valencia). Serie de Trabajos Varios del Servicio de Investigación Prehistórica 25, Diputación Provincial de Valencia. Valencia.

García Cano, J. M.; Page, V.; Gallardo, J.; Ramos, F. y Hernández, E. 2008: El mundo funerario ibérico en el Altiplano Jumilla-Yecla (Murcia): la necrópolis de El Poblado de Coimbra del Barranco Ancho. Investigaciones de 1995-2004, II. Fundación Adendia. Murcia.

García, J.; Zamora, M. D. y Pujol, J. 1998: “Armament i societat a la Laietània ibérica". Los Iberos, Príncipes de Occidente. Las estructuras de poder en la sociedad Ibérica”. Saguntum extra-1: 309-325.

Iborra, M. P. 2004: La ganadería y la caza del Bronce Final al Ibérico Final en el territorio valenciano. Serie de Trabajos Varios del Servicio de Investigación Prehistórica 103, Diputación Provincial de Valencia. Valencia.

Iborra, M. P. 2012: "El material faunístico recuperado en el depósito votivo de Libisosa". En H. Uroz (ed.): Prácticas rituales, iconografía vascular y cultura material en Libisosa (Lezuza, Albacete). Nuevas aportaciones al ibérico final del Sudeste. Universidad de Alicante. Alicante: 199-213.

Iborra, M. P. 2014: "El material faunístico". En A. Lorrio (ed.): La necrópolis orientalizante de Boliche (Cuevas de Almanzora, Almería): la colección Siret del Museo Arqueológico Nacional. Bibliotheca Archaelogica Hispana 43, Real Academia de la Historia. Madrid: 225-228.

Karkanas, P. 2007: "Identification of Lime Plaster in Prehistory Using Petrographic Methods: A Review and Reconsideration of the Data on the Basis of Experimental". Geoarchaeology 22: 775-796.

Kurz, G. 2003: "Los hierros de Cancho Roano". En S. Celestino (ed.): Cancho Roano VIII: Los materiales arqueológicos $I$. Instituto de Arqueología de Mérida-CSIC, Junta de Extremadura y Bartolomé Gil Santacruz. Mérida: 293-366.

Lorrio, A.; Iborra, M. P.; Sánchez de Prado, M. D. 2014: "Depósitos rituales de fauna en el oppidum prerromano de El Molón (Camporrobles, Valencia). Archivo de Prehistoria Levantina XXX: 213-238.

Mancebo, J. 2000: "Análisis de los objetos metálicos en el período orientalizante y su conexión con el mundo fenicio. Los cuchillos afalcatados". Actas del IV Congreso Internacional de Estudios fenicios y Púnicos (Cádiz 1995), IV: 1825-1834. Cádiz.

March, R. J. 1995: "L'étude des structures de combustion en archéologie: un détour vers l'histoire". Annales de la Revue Fyssen 10: 53-68.

Olcina, M. H.; Martínez, A. y Sala, F. 2009. La Illeta dels Banyets (El Campello, Alicante). Épocas ibérica y romana I. Historia de la investigación y síntesis de las intervenciones recientes (2000-2003). Serie Mayor 7, Museo Arqueológico de Alicante. Alicante.

Pérez Jordà, G.; Ferrer García, C.; Iborra Eres, M. P.; Ferrer Eres, M. A.; Carrión Marco, Y.; Tortajada Comeche, G. y Soria Combadiera, L. 2011: "El trabajo cotidiano. Los recursos agrarios, la metalurgia, el uso de la madera y las fibras vegetales". En H. Bonet y J. Vives-Ferrándiz (eds.): La Bastida de les Alcusses. 1928-2010. Diputación Provincial de Valencia. Valencia: 94-137.

Quesada, F. 1997: El armamento ibérico. Estudio tipológico, geográfico, funcional, social y simbólico de las armas en la Cultura Ibérica (siglos VI-I a.C.). Monographies Instrumentum 3, Ed. Monique Mergoil. Montagnac.

Quesada, F. 1998: "El guerrero y sus armas". Museo de El Cigarralejo (Mula, Murcia). Monográfico del Boletin de la Asociación Española de Amigos de la Arqueología 38: 187-217.

Quesada, F. 2010a: "Las armas en los poblados ibéricos: teoría, método y resultados". En F. Quesada, M. Navarro y F. Cadiou (eds.): De armas, de hombres y de dioses. Gladius XXX: 17-42. Madrid.

Quesada, F. 2010b: "Las armas de la sepultura 155 de la necrópolis de Baza”. En T. Chapa e I. Izquierdo 
(eds.): La dama de Baza. Un viaje femenino al más allá. Ministerio de Cultura. Madrid: 149-169.

Quesada, F. 2011: "El armamento de un poblado ibérico del siglo IV a.C.: una oportunidad excepcional". En H. Bonet y J. Vives-Ferrándiz (eds.): La Bastida de les Alcusses. 1928-2010. Diputación Provincial de Valencia. Valencia: 196-219.

Quesada, F.; Zamora, M. y Requena, F. 2000: "Itinerant smiths in the Iberian Iron Age? $\left(6^{\text {th }}-2^{\text {nd }}\right.$ centuries BC)". En M. Feugère y M. Gustin (eds.): Iron, Blacksmiths and Tools. Monographies Instrumentum 12, Ed. Monique Mergoil. Montagnac: $15-19$.

Ridgway, D. 1997: "Nestor's cup and the Etruscans". Oxford Journal of Archaeology 16 (3): 325-344.

Soler, B. 2003: Estudio de las estructuras de combustión prehistóricas: una propuesta experimental:
Cova Negra (Xàtiva, Valencia), Ratlla del Bubo (Crevillent, Alicante) y Marolles-sur-Seine (Bassin Parisien, Francia). Serie de Trabajos Varios del Servicio de Investigación Prehistórica 102, Diputación Provincial de Valencia. Valencia.

Tortajada, G. 2011: "El montaje de los batientes de las puertas". En H. Bonet y J. Vives-Ferrándiz (eds.): La Bastida de les Alcusses. 1928-2010. Diputación Provincial de Valencia. Valencia: 8081.

Vives-Ferrándiz, J. 2013: "Del espacio doméstico a la estructura social en un oppidum ibérico. Reflexiones a partir de la Bastida de les Alcusses". En S. Gutiérrez e I. Grau (eds.): De la estructura doméstica al espacio social. Lecturas arqueológicas del uso social del espacio. Universidad de Alicante. Alicante: 95-111. 